\title{
In situ delta ferrite estimation and their effects on FCPR at different orientations of multipass shielded metal arc welded SS304L
}

\author{
Mudaser Ullah ${ }^{\mathrm{a}, *}$, Chuan Song $\mathrm{Wu}^{\mathrm{a}}$, Masood Shah ${ }^{\mathrm{b}, \mathrm{c}}$ \\ a MOE Key Lab for Liquid-Solid Structure Evolution and Materials Processing, Institute of Materials Joining, Shandong University, Jinan 250061, PR China \\ ${ }^{\mathrm{b}}$ Mechanical Engineering Department, University of Engineering \& Technology, Taxila, Pakistan \\ ' Université de Toulouse, INSA, UPS, Mines Albi, ISAE, ICA, Route de Tiellet, Campus Jarlard, Albi, France
}

\begin{abstract}
Solidification and re-solidification with subsequent phase transformation in different welding zones of multipass weldment play a vital role to define mechanical properties of joint structures. To avoid from penetration defects and inclusion contamination in molten metal pool, multipass shielded metal arc weld-ing (SMAW) of SS304L is performed in this research using E308L filler metal. The objective of this research is to investigate out the multiple welding passes effects on microstructural evolution, in situ delta ferrite percentage and different mechanical properties. A metallurgical microscope is used to examine the delta ferrite phase in austenite. Instead of depending on general ferrite number (FN) obtained through rigorous physical attempts, a MATLAB $^{\circledR}$ code for image processing is developed to estimate the local percentage of delta ferrite, within the austenitic phase. To reveal delta ferrite effects, its local percentage is discussed in relation to various properties. With the help of this technique, a good estimation is also made to detect the localized delta ferrite morphologies. The fusion zone (FZ) solidified in ferritic-austenitic mode (FA mode) comprises two basic delta ferrite morphologies; lacy and vermicular. Grain growth behavior and ferritic percentage of base metal (BM), heat affected zone (HAZ) and fusion zone (FZ) are discussed in single, double and triple pass weldments. Effects of delta ferrite percentage and morphology on fatigue crack initiation as well propagation are also investigated in different zones of each pass weldment. Fatigue crack propagation rate (FCPR) in different orientation with respect to welding zones is checked and it is noticed that propagation rate is much lower in perpendicular direction as compared to parallel one. Due to specific microstructural pattern, HAZ has greater fatigue crack propagation rate (FCPR) in comparison to BM and FZ. Fatigue crack propagation found highest resistant in triple pass weldment due to high con-centration of lacy ferrites. However, in some cases it is found that crack mechanics is actually responsible instead of microstructural effects.
\end{abstract}

\section{Introduction}

The major portion of stainless steel (SS) family which covers almost $60-70 \%$ of its structural application range due to most suitable mechanical properties, corrosion resistance and an excellent level of fabricability is austenitic stainless steel (ASS) [1]. Due to its vast usage in structure forming in different versatile fields, a fine flawless joining mechanism is always sought, which can fulfill this purpose on bulk basis. Normally the most widely used and reliable permanent metal joining process in structural applications is welding [2]. Shielded metal arc welding (SMAW) or simply stick welding is the most frequently used welding type in different AISI

\footnotetext{
* Corresponding author.

E-mail address: mudaser_me150@yahoo.com (M. Ullah).
}

grades of stainless steel family due to its less expensive, easily controllable and a pretty good portable nature [3]. The resultant weldments of mentioned welding type have acceptable mechanical properties in accordance to application demands as well as a fine resistance to different failure phenomenon [4]. However, slag inclusion due to flux coating involvement and higher spatter are the key factors to reduce the weld bead quality of SMAW [5]. Austenitic stainless steel (ASS) grades having low carbon contents are famous due to their weldability and microstructure dependent properties. High temperature as a result of SMAW is responsible for evolving of microstructural variations at different zones of weldments. In case of pure ASS, sudden cooling and rapid solidification of molten metal pool at fusion zone causes solidification shrinkage. A fine and uniform distribution of delta ferrite in ASS yields good results against shrinkage failure of FZ [6]. The appearance, shape and orientation density of delta ferrite is highly dependent on the chemical 
composition of base metal (BM), filler rod and cooling rate of FZ as well. Variations in heat input as a result of multipass (MP) welding also play a deterministic role in microstructural shifting and properties variance [7]. Clusters of delta ferrite appearance at heat affected zone (HAZ) are due to rapid re-solidification of molten metal. Hot cracking is taken place due to inequality of thermal expansion between the delta ferrite at HAZ and the solidifying ASS at FZ [8]. Delta ferrite has a low thermal expansion as compared to austenitic steel and due to this thermal stresses generated leading to failure of weldments $[9,10]$. The difference in thermal expansion of ferritic and austenitic phase causes the generation of thermal stresses and due to these stresses FZ always experiences the induction of residual stresses exactly at boundaries of the zone in outward direction [11]. These residual stresses play a vital role to define the fatigue life of the component $[12,13]$. To control hot cracking, ferrite to austenite ratio at FZ is considered and it is estimated that $3-12 \%$ ferrite contents are accepted as a normal range [14]. Under different loading conditions, these ferrites are shifted to a new phase named as sigma phase and this phase has total different effects on the physical properties of the weldment [15]. Welding type, welding parameters like voltage, current, welding speed and number of passes have individually distinct effects on heating of the specimen [16]. Ferrite phase appears in ASS mostly in two shapes, lacy and vermicular, and Brooks et al. found that lacy ferrite always formed in ferrite single phase solidification mode (F mode) instead of ferritic-austenitic solidification mode (FA mode) [17].

Under cyclic loading conditions, welded joints are always vulnerable to fatigue damage. This type of failure is always started with a crack nucleation and welded sites are more prone to fatigue crack nucleation, resultantly decreasing the service life of component [18]. The well-known factors affecting the fatigue life of a welded machine part are stress concentration due to weld bead geometry, surface defects, thermal stresses, tensile residual stresses and microstructural variations at different zones of weldment [19]. Most of the already performed research is geometry-dependent, mechanics based and factors affecting on it. Oh et al. studied the fatigue nature of welded Ti-6Al-4V with different types of processes [20]. Hasçalik et al. studied the fatigue behavior of friction stir welded SS304 and AISI 4340 [21]. Mudaser et al. investigated the fatigue crack propagation in TIG welded AA2219 and microstructural effects on the fatigue crack nucleation [22]. Masood Shah et al. studied the residual stresses generated due to welding of tool steel [23]. A series of experiments are conducted by Tsay et al. to study the fatigue crack propagation rate (FCPR) in FZ, HAZ and BM [24]. Jiang et al. studied the weld repairs effects on mechanical properties and microstructure of steel plate. They investigated that by increasing ferrite number, transverse residual stresses are decreased but the hardness of the specimen is enhanced due to $\mathrm{Cu}$ and Fe diffusion [25]. Rho et al. and Hong et al. successfully developed a relationship between ratios of $\delta$-ferrite to austenite and low cycle fatigue (LCF) $[26,27]$. Lin et al. investigated that ferrite percentage up to $31.5 \%$ is beneficial to save the martensitic steel from thermal fatigue [28]. Rho et al. also investigated the effects of presence of $\delta$-ferrite in austenite phase and its association with LCF [27]. After a comprehensive systematic literature review it is found, a general fatigue life estimation and fatigue crack propagation behavior is studied by different researchers. And overall effects of ferrite number (FN) on fatigue life for different materials are explored [29-31]. Not one effort is made to find out the differences in percentage generation of $\delta$-ferrite in different passes of SMAW and its effects on mechanical as well as fatigue properties of SS304L. As the material properties vary so abruptly in different zones of weldment so it is not much fruitful to find out ferrite number (FN) by volume and then relate it to fatigue behavior corresponding to that zone. So, in this paper, the local percentage of $\delta$-ferrite at different zones of weldment is

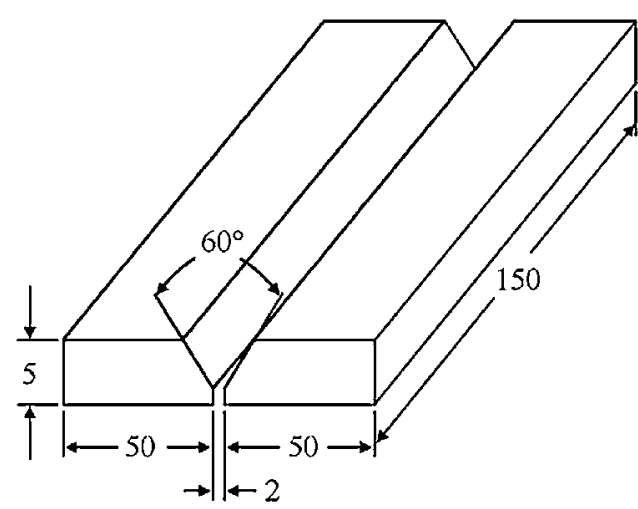

Fig. 1. 'V' notch cutting for preparation of welding joints.

investigated and its relation to fatigue behavior is also studied. FCPR at different orientation of multipass stick welded SS304L is also evaluated in this research work. A correlation is discussed between the local ferrite percentage, generated after different welding passes and tendency to fatigue crack propagation.

\section{Experimental}

\subsection{Welding}

A cold-rolled plate (AISI304L) of $8 \mathrm{~mm}$ thickness was cut into two pieces by using abrasive cutter. According to dimensions of $\mathrm{V}$ type butt joint as shown in Fig. 1, the edges of two sectioned pieces were machined with the help of a milling cutter. Shielded metal arc welding (SMAW) was used to weld these steel plate pieces, placed on a flat surface, using AWS E308L electrode.

The chemical composition of base metal and weld deposit after subjected welding type is represented in Table 1.

Three types of weldments (single pass, double pass, and triple pass) were performed to fill the V-grove of butt joint with molten metal to cope the range and nature of experiments required for this research. Welding process was done according to welding qualification procedure and a detail of welding parameters for each weldment is represented in Table 2.

To avoid from any geometrical and surface structure influence on experimental results, superficial protruded faces of weld beads were removed by milling machine keeping its cutter speed minimum to abstain from unwanted mechanical and thermal residual stresses. The welded plates were carefully inspected by ultrasound technique by following AWS D1.6-99 recommendations.

\subsection{Mechanical properties}

From the plates welded through different passes, tensile specimens according to ASTM E8M-04 were parted off with the help of electric discharge machine (EDM) wire cut (Model: DK7740). The weld nugget zone (FZ) of each pass weldment must be equally distributed on both side of longitudinal center line as shown in Fig. 2.

MTS-810 was used to find out the tensile properties of each type of weldment. The experimental setup for tensile testing is presented in Fig. 3.

Hardness values were obtained for every zone of each pass weldment by using Vicker's micro hardness tester (Model: HMV-2T). On both side of center of FZ, hardness was tested with a load of $0.5 \mathrm{~N}$. Charpy impact tests were also performed for each pass weldment at room temperature. The absorbed energy by different types of specimens is regarded as impact toughness of their respected weldment. 
Table 1

Chemical composition of base metal and weld deposit (Filler: E308L).

\begin{tabular}{|c|c|c|c|c|c|c|c|c|c|c|c|c|c|c|c|}
\hline Type & $\mathrm{Fe}$ & $\mathrm{C}$ & $\mathrm{Si}$ & Mn & $\mathrm{P}$ & $\mathrm{S}$ & $\mathrm{Cr}$ & Mo & $\mathrm{Ni}$ & $\mathrm{V}$ & $\mathrm{Cu}$ & $\mathrm{Ti}$ & $\mathrm{Nb}$ & Co & $\mathrm{N}$ \\
\hline Base metal & Balance & 0.055 & 0.634 & 1.630 & 0.030 & 0.007 & 18.197 & 0.217 & 7.990 & 0.084 & 0.306 & 0.007 & 0.001 & 0.126 & 0.070 \\
\hline Weld deposit of E-308L filler & Balance & 0.039 & 0.345 & 1.817 & 0.028 & 0.007 & 19.695 & 0.058 & 9.150 & 0.070 & 0.110 & 0.006 & 0.009 & 0.071 & 0.081 \\
\hline
\end{tabular}

Table 2

Shielded metal arc welding parameters.

\begin{tabular}{|c|c|c|c|c|c|c|}
\hline \multirow[t]{2}{*}{ Parameters } & \multirow[t]{2}{*}{ Single pass weldment } & \multicolumn{2}{|c|}{ Double pass weldment } & \multicolumn{3}{|c|}{ Triple pass weldment } \\
\hline & & 1st pass & 2nd pass & 1st pass & 2nd pass & 3rd pass \\
\hline Electrode diameter (mm) & 4 & 4 & 4 & 4 & 4 & 4 \\
\hline Welding speed (mm/min) & 180 & 190 & 195 & 190 & 190 & 200 \\
\hline Voltage (V) & 25 & 20 & 20 & 18 & 18 & 20 \\
\hline Current (A) & 120 & 100 & 100 & 100 & 100 & 100 \\
\hline Arc gap (mm) & 3 & 3 & 4 & 3 & 4 & 4 \\
\hline Polarity & SP & SP & SP & SP & SP & SP \\
\hline Heat input (kJ/mm) & 1 & 0.63 & 0.62 & 0.57 & 0.57 & 0.60 \\
\hline
\end{tabular}

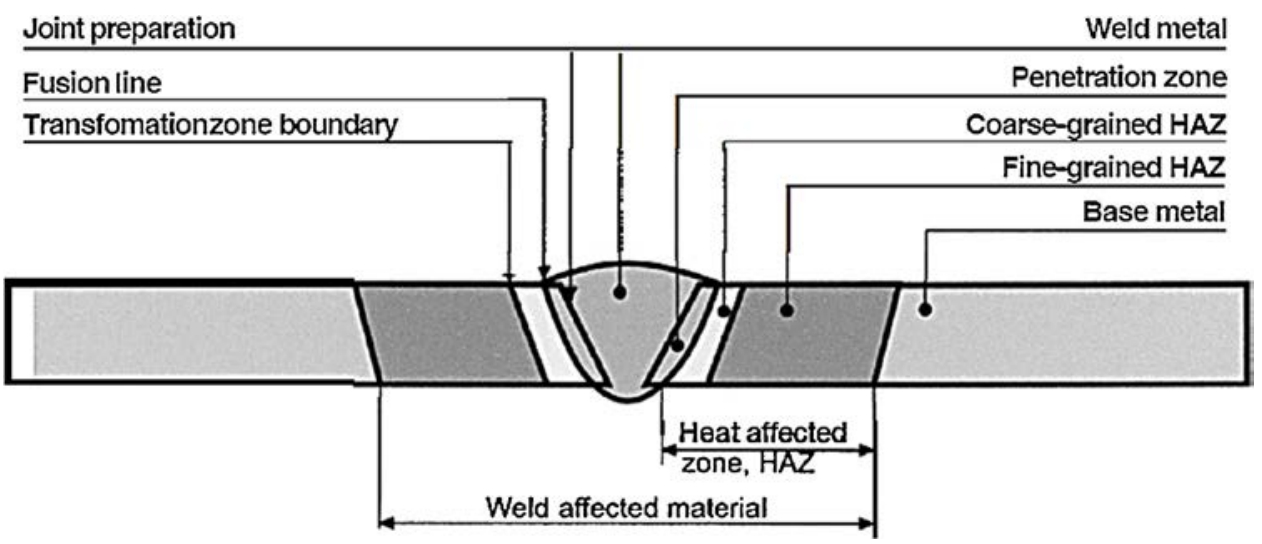

Fig. 2. Different zones formation as a result of welding.

\subsection{Metallography}

Olympus DP-20, an optical metallurgical microscope furnished with image analyzer software, was used to perform the metallography of welded specimens. Small pieces of each welding zone of different weldments were cut-off and further surface preparations techniques were made to visualize the grain growth behavior and distribution of delta ferrite. Firstly the specimens were made scratches free by using different emery papers, number ranging from 120 to 2000 grits. After this the specimens were creamed with universal polishing paste (Model no. UPP 841-0602) and rubbed with leather pad. Finally the specimens were polished with synthetic diamond crystal paste of grades $(\mathrm{W}-40)$ and $(\mathrm{W}-1.5)$ respectively on a rotating polishing machine. For fine detection of delta ferrite distribution pattern in SS304L the ASM standards recommend electrolytic etching. The details of etching are mentioned here; $20 \mathrm{~g} \mathrm{NaOH}$ and $100 \mathrm{~mL}$ distilled water, electrolytic etch at $20 \mathrm{~V}$ dc for 5-20 s to reveal delta ferrite presence in austenitic stainless steel.

\subsection{Fatigue testing}

A series of fatigue crack propagation rate (FCGR) experiments were conducted on a servo hydraulic universal testing machine (Model: MTS 810). The testing parameters are shown in Table 3. For fatigue test, Compact-tension ' $C(T)$ ' specimens were fabricated from the welded plates according to dimensions shown in Fig. 4.

The specimens were cut in such a way that each pass weldment has four different orientation of FZ with respect to notch tip, a point of fatigue crack initiation as shown in Fig. 4. The double wedgeshaped notch edge was fabricated through a special electrode in die-sinking EDM. The crack lengths measuring is made by two techniques, optically as well as calculated from the machine data according to ASTM standards E399. MTS 810 stored crack length history through crack opening displacement (COD) gauge (Model: 634.31 F24), installed at the mouth of notch. The crack length is calculated by using Eq. (1).

$$
\begin{aligned}
& \frac{a}{W}=1.000-4.500 U+13.157 U^{2}-172.551 U^{3} \\
& \quad+879.944 U^{4}-1514.671 U^{5}
\end{aligned}
$$

whereas,

$U=\frac{1}{\left[1+\sqrt{\left(\left(E^{\prime} B V_{\mathrm{m}}\right) / P\right)}\right]}$

Here ' $a$ ' shows crack length, $E^{\prime}$ represent the young's modulus of specimen material in $\operatorname{Pa}\left(E^{\prime}=E\right.$ when there is plane stress conditions, and for plane strain conditions it is represented as $E^{\prime}=E /\left(\left(1-v^{2}\right)\right)$, $v$ is passion ratio, ' $B$ ' and ' $W$ ' are thickness and width of specimen

Table 3

Fatigue testing parameters.

\begin{tabular}{lc} 
Max. load $(\mathrm{kN})$ & 7 \\
Load ratio, $R$ & 0.1 \\
Frequency $(\mathrm{Hz})$ & 10 \\
Temperature $\left({ }^{\circ} \mathrm{C}\right)$ & 25 \\
\hline
\end{tabular}




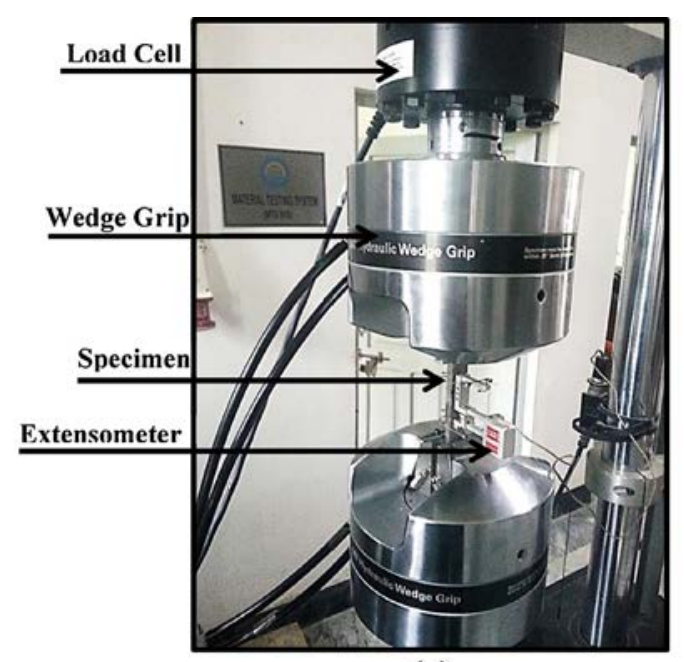

(a)

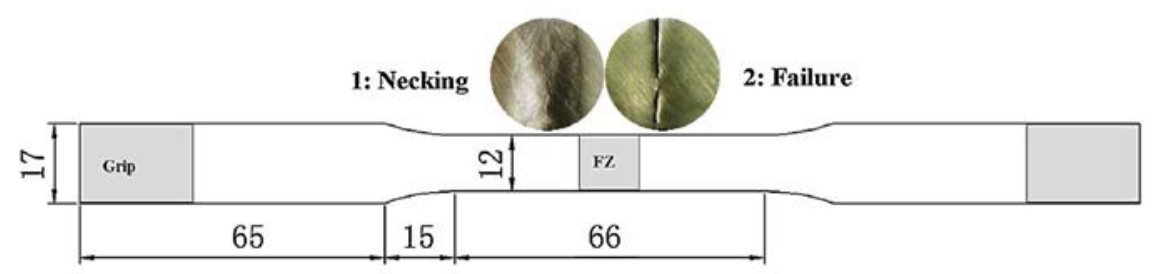

(b)

Fig. 3. (a) Tensile testing experimental setup. (b) Dog bone specimen for tensile testing.

in meter respectively, $P$ is applied load $(\mathrm{kN})$ and $V_{\mathrm{m}}$ represents the crack mouth opening compliance measurements ( $\mathrm{m})$.

The second technique was a direct measuring of crack length with the help of a microscope mounted on a movable scale as shown in Fig. 5.

This microscope is directly connected to a computer having a graduated strip on screen and it is exactly parallel to specimen notch image. Initial crack location is noted on microscope scale and crack tip position is marked on graduated strip and further measuring is made with respect to these reference points. After a specific number of cycles the crack length is noted and at this moment the frequency is reduced from 10 to $2 \mathrm{~Hz}$ for clear detection of crack tip position.

\section{Results and discussion}

\subsection{Microstructure}

In this section, microstructure evolved as a result of different welding passes is presented and discussed. The microstructure variance among different passes weldments is basically due to heat input history at FZ, solidification and re-solidification behaviors, cooling rate, phase morphologies, percentage amount and distribution pattern of delta ferrite particles. Heat source motion and inclusion presence also play their role to alter the microstructure, resultantly properties of weldment are shifted. As the study of delta ferrite is prime objective of this section, so its local percentage is calculated in different zones and for different passes of weldments. Massive literature is available on over all ferrite number (FN) of welding zones. No one tried to find its local percentage variance as a result of multi passes SMAW. For this purpose, a MATLAB ${ }^{\circledR}$ code for image processing is generated successfully. A good resemblance is found between the FN obtained through different electronic devices and average of all local FN's calculated through percentage (obtained by image processing) for a specific welding zone. Less than $2 \%$ deviation between these two results is ignored on the sake of interesting information about local ferrite percentage values within a zone. However, selection of etchant and its final dilution percentage (also of constituents) is achieved after many efforts to reveal only delta ferrite with in austenitic phase. Inaccuracy in surface flatness, exposure of other microstructural species and surface scratches may reduce the adaptability of this technique.

\subsubsection{Single pass}

Three distinct microstructural zones are formed as a result of single pass SMAW as shown in Fig. 6(a). Depending on chemical composition of weld deposit, generally four basic solidification modes are identified in austenitic steel as shown in Fig. 7. Molten metal pool at FZ of 1-pass welding followed the ferritic-austenitic mode (FA mode) of solidification.

The microstructure of FZ comprises two morphologies of ferrite phase, lacy and vermicular, as shown in Fig. 6(b). The repeating alternate manners of these morphologies depict their almost constant ratio which shows the less dependency of ferrite species morphology on chemical composition. Heat input is the main factor to alter the shapes of ferrites. During welding the temperature gradient is successively decreases from arc center to BM. So the boundaries between HAZ and FZ are bearing high temperature as compared to those between BM and HAZ. Due to this temperature difference the lacy ferrite band near HAZ turned into short, coarsen ferrites while the ferrite on the other boundary of HAZ are found in fine size as shown in Fig. 6(a). The clustering of delta ferrite at HAZ is due to rushing of melted titanium and chromium, ferrite stabilizers, toward welding pool from BM. Due to rapid solidification, these accumulate at the site of HAZ and promote the origination of delta ferrite. Due to high heat input, mostly short, coarse ferrites near to FZ boundaries are preferentially turned into austenitic 


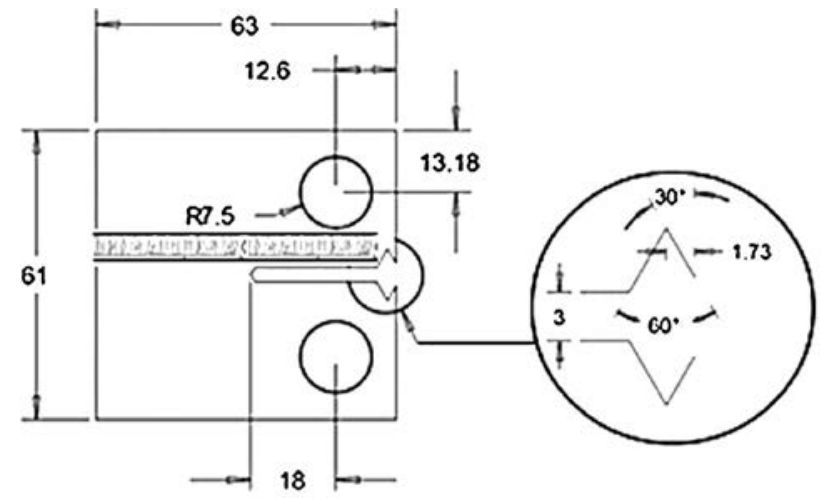

(A)

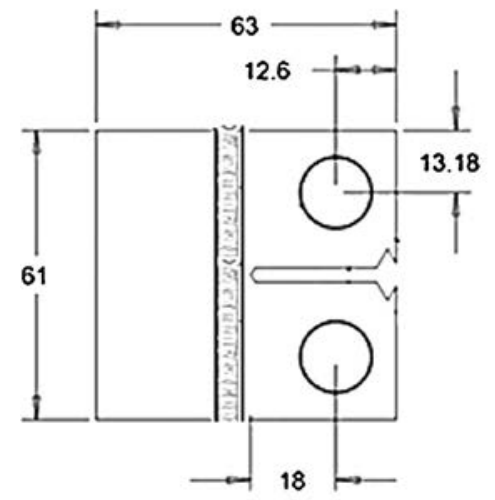

(C)

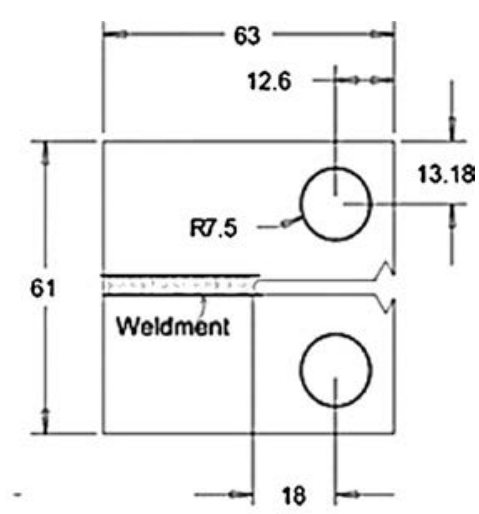

(B)

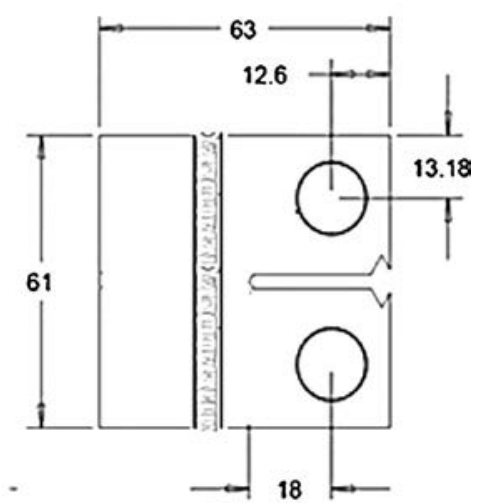

(D)

Fig. 4. $C(T)$ specimens for fatigue testing. (a) Crack within HAZ. (b) Crack within WNZ. (c) Crack perpendicular to WNZ. (d) Crack perpendicular to HAZ.

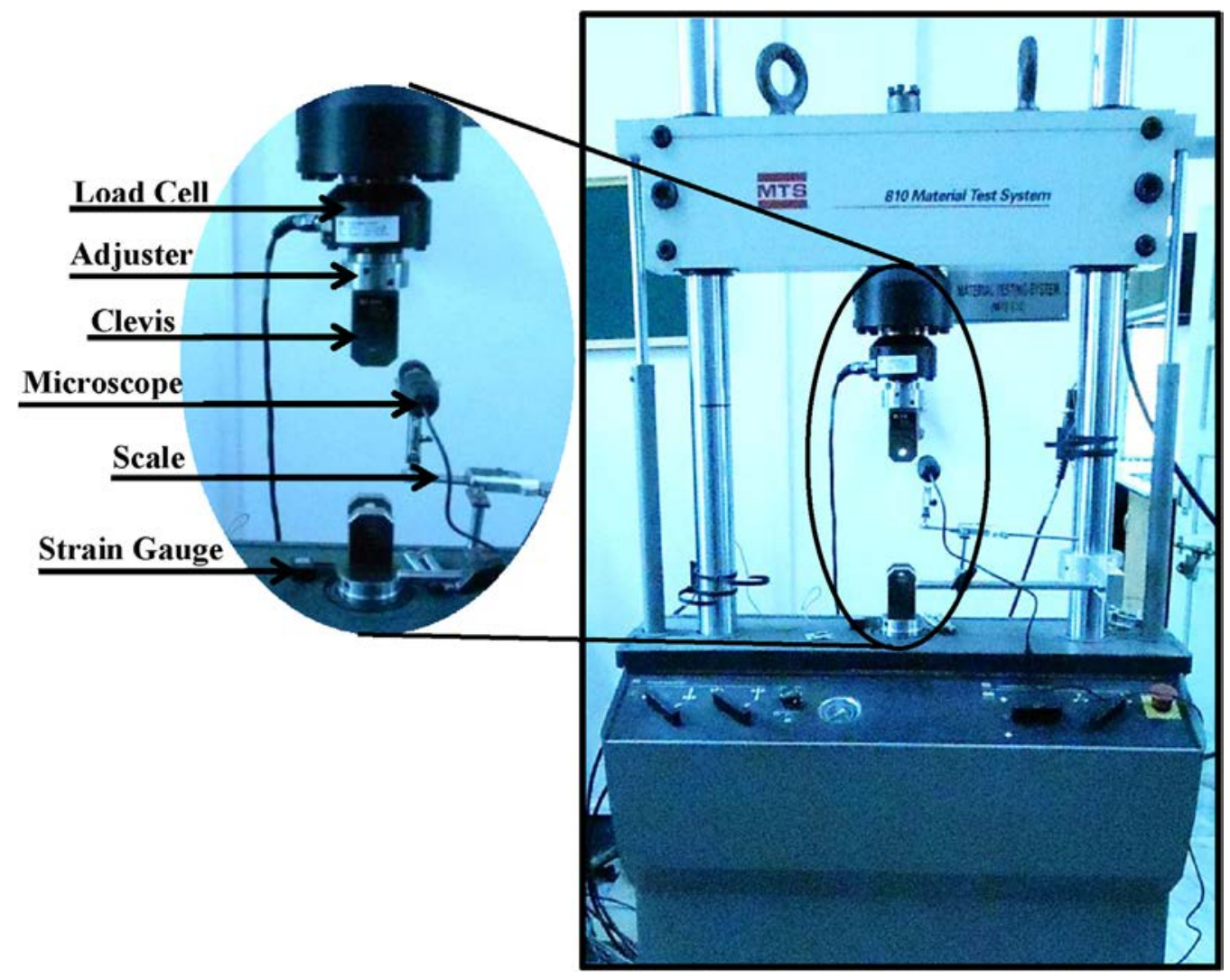

Fig. 5. Experimental setup for direct crack length measuring through a microscope and a movable scale. 

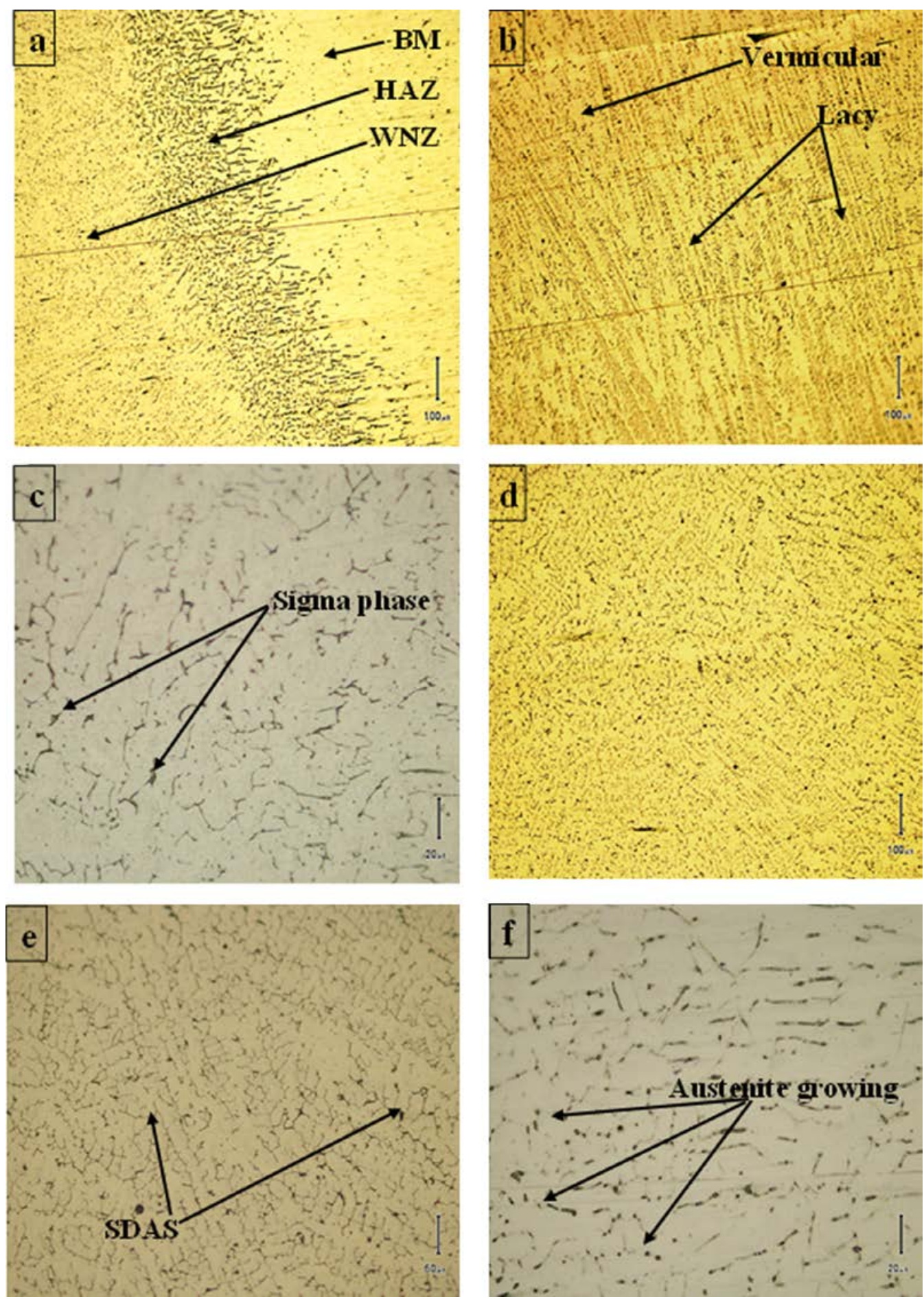

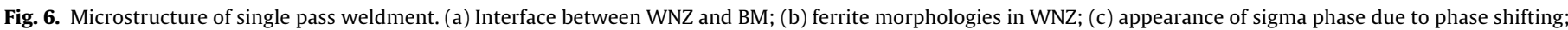
(d) WNZ at bottom of the notch; (e) mature dendritic structure in WNZ (top of the notch); (f) ferrite clustering in HAZ.

phase. When this phase shifting is done enormously then a thin pure austenitic line is observed, seeming to separate the two zones as shown in Fig. 6(a). Some short ferrites of HAZ located at high heat input areas are turned to a new phase named as sigma $(\sigma)$ ferrite (Fig. 6(c)). Sigma ferrite is most unwanted phase for proper workability of welded low carbon steel, making the specimen more prone to thermal cracking. As in single pass weldment the whole notch is filled with molten metal in single traveling of SMAW electrode so high amperage of current and a relatively low welding speed is advised for a porosity free uniform welding. High current and low welding speed yields into high input to $\mathrm{FZ}$, leading to a slow cooling rate. It is considered that this high heat input might be helpful to reduce the residual stresses generated due to variance in thermal expansions of delta ferrite and austenitic phase. In single pass SMAW, the temperature of molten pool at the root of the notch is not same to the temperature of superficial surface of the molten metal pool. At the notch root, solidification starts earlier. A dendritic structure is observed with a small tendency to grain growth behavior as shown in Fig. 6(d). It is also observed from Fig. 6(d) that secondary dendritic arm spacing (SDAS) is increased 


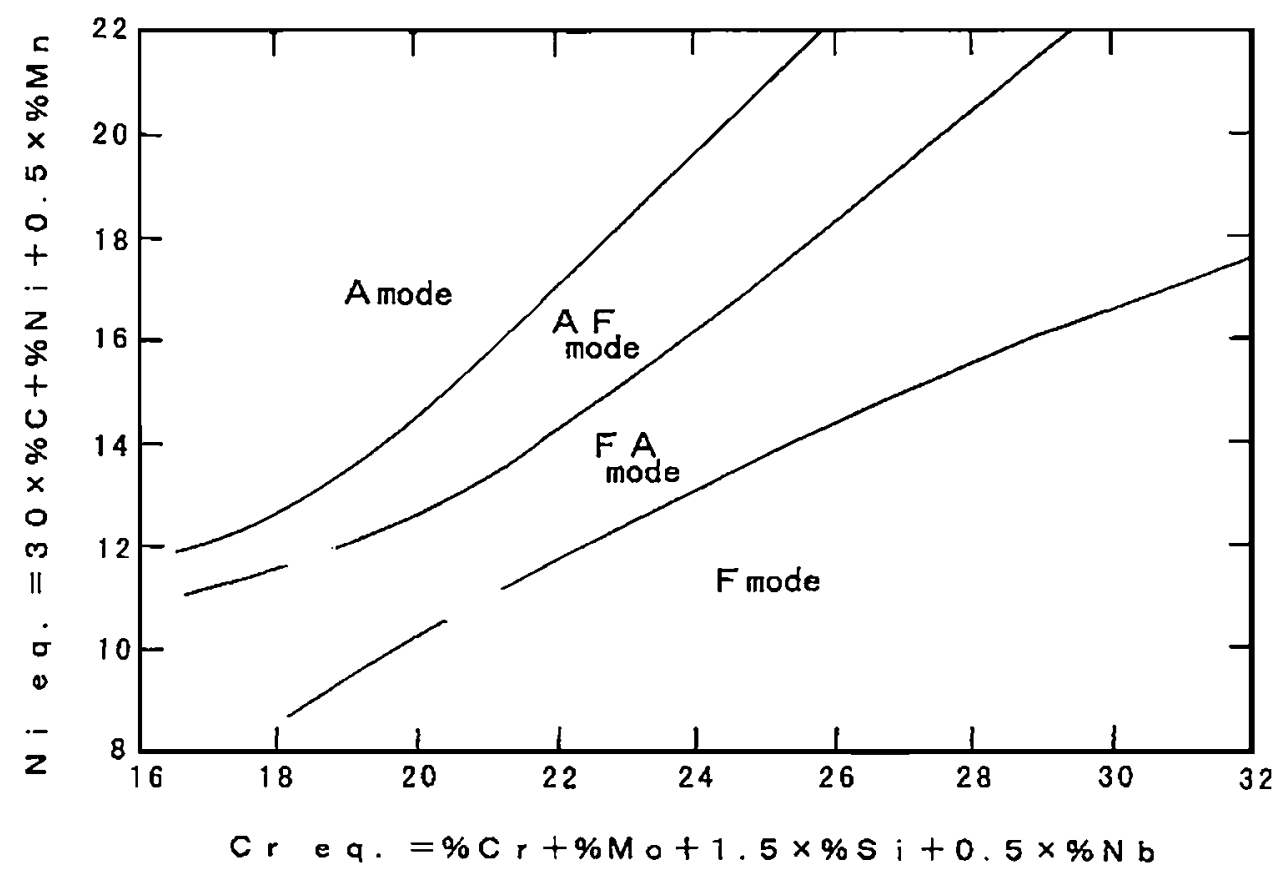

Fig. 7. Four distinct modes of solidification in austenitic stainless steel.

from notch root to top side. SDAS follows Eq. (3), which shows these are highly dependent on cooling rate of solidifying metal.

$\mathrm{SDAS}=\mu_{\mathrm{o}} t_{\mathrm{f}}^{0.34}$

where, $\mu_{\mathrm{o}}=$ material specific constant, $t_{\mathrm{f}}=$ solidification time.

The distribution of delta ferrite in different zones of single pass welding is represented in Fig. 8. The maximum delta ferrite is shown in HAZ and this percentage is suddenly decreased on both side of the zone as shown Fig. 8(a). On one side, it is due to migration of melted ferrite stabilizer toward heat source creating a ferrite free zone. While on the other side absence of ferrites is due to size reduction and phase shifting on account of excessive heat. There is non-uniformity in size and diminishing nature of HAZ is also observed in single pass SMAW (Fig. 8(b)). It might be due to uneven temperature distribution or accumulation of some austenite stabilizer. The local percentage of delta ferrite in $\mathrm{FZ}$ at top of notch is shown in Fig. 8(c). The average value of delta ferrite obtained through this technique is compared with the value gained through J5-660 Magne-Gage.

There is only $0.83 \%$ difference, and this extra value is due to recognition of carbides as a particle of delta ferrite. These carbides are preferentially formed at the edges of ferrites having vermicular morphology. From Fig. 8(c), it is even very easy to guess percentage estimate of different morphologies of delta ferrite due to local nature of this technique.

\subsubsection{Double pass}

In two pass SMAW, individual characteristic of each pass and their mutual cumulative effects on evolved microstructure are studied and shown in Fig. 9. As the ' $V$ ' notch of specimen is filled in two attempts in this weldment so due to solidification after first pass and re-solidification after second pass affects the microstructural pattern as well as concentration of delta ferrite at different zones. In FZ of second pass, which is on the top of notch, the austenitic phase is relatively higher as compared to single pass weldment and it is due to planer growth of austenite as shown in Fig. 9.

The dominant ferrite morphology is vermicular; however lacy ferrites are also present in the form of bands. The high concentration of vermicular ferrites is due to phase shifting of ferrites situated at the cores of austenite. This inward austenitic growth is suppressed by the minimized interfacial energy between the ferrite and austenite. Absence of any crystallographic orientation relationship between the newly generated austenite and primary ferrite is responsible for reduction of this interfacial energy. Crystallographic mismatching is shown in Fig. 9 where the solidification direction of austenite between the edges of vermicular ferrites is not the same to austenitic pattern near the lacy ferrite bands. A clear dendritic structure is also observed in FZ of second pass. Primary ferrites are seen on the boundaries of dendrites. The interesting phenomenon featured to this zone is that the vermicular ferrites are present at the cores of austenitic phase while the lacy ferrites are situated at the cores of dendritic structure. The microstructure between first pass and second pass shows that due to excessive heat input and re-solidification, ferrites are turned to particle shaped and engulfed by the austenitic patches as shown in Fig. 9. The reheating of first pass is also responsible for phase shifting. Generation of carbide is more at FZ of second pass as compared to first pass because ferrite has higher solubility rate for alloying elements as compared to austenite. HAZ formed between the FZ of second pass and BM is wider as compared to that formed between FZ of first pass and BM (Fig. 9). The reason is the higher time taken by the welding process to fill the comparatively wider upper portion of the notch with respect to deeper narrow one. HAZ associated with first pass has shorter, coarsen and closely packed ferrites as compared to ferrites present in HAZ linked to first pass. At the periphery of second pass HAZ, a fine grain growth is observed with dense ferrite accumulation at the boundaries. It is notable that the HAZ of first pass has a considerable amount of sigma ferrite which shows that due to reheating an acute phase shifting is taken place. Iron carbides are also present here in some amount. FZ of second pass has columnar shape delta ferrites near its HAZ. Between these columns, austenite is solidified in pre-mature dendritic shape. While the FZ of first pass near the HAZ comprises mostly austenitic phase having epitaxial growth with dipped, particle shaped ferrites.

Percentage of delta ferrite in different zones of second pass SMAW is shown in Fig. 10. 


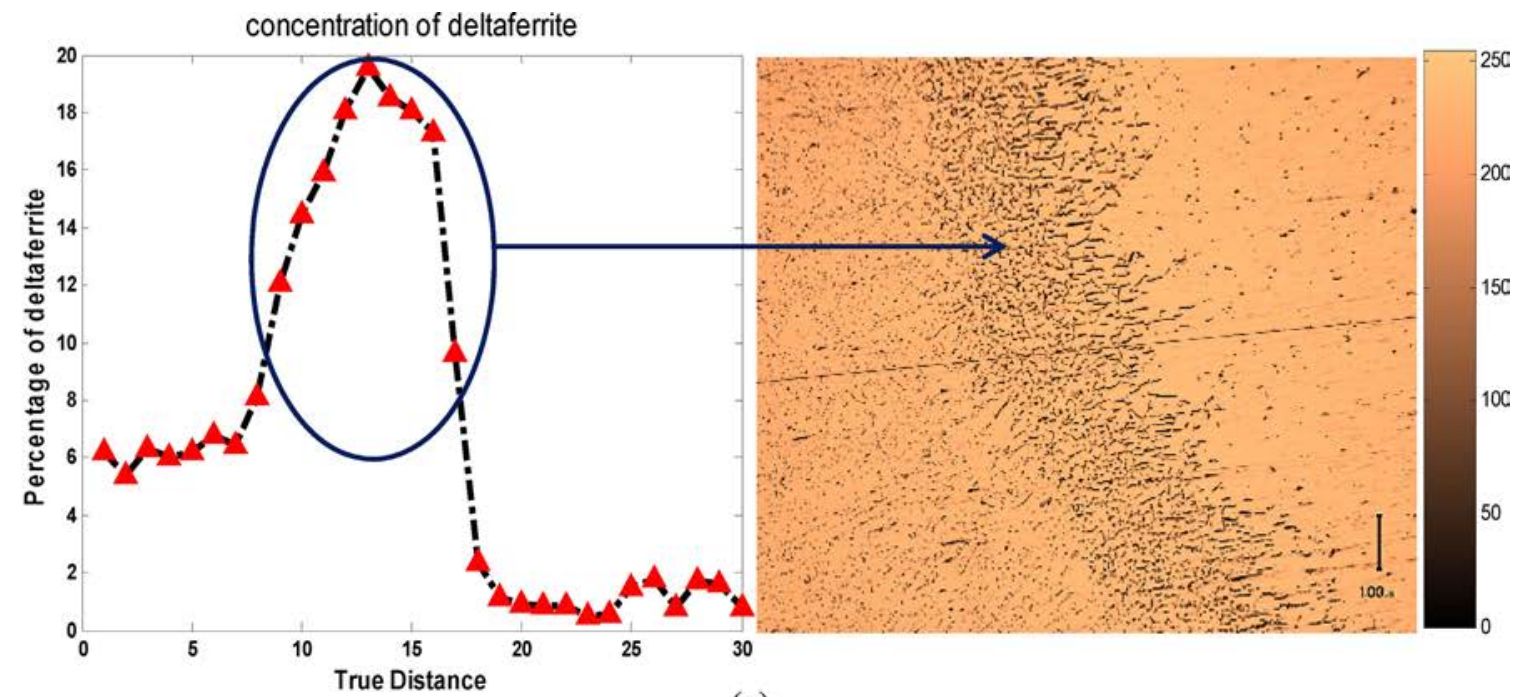

(a)

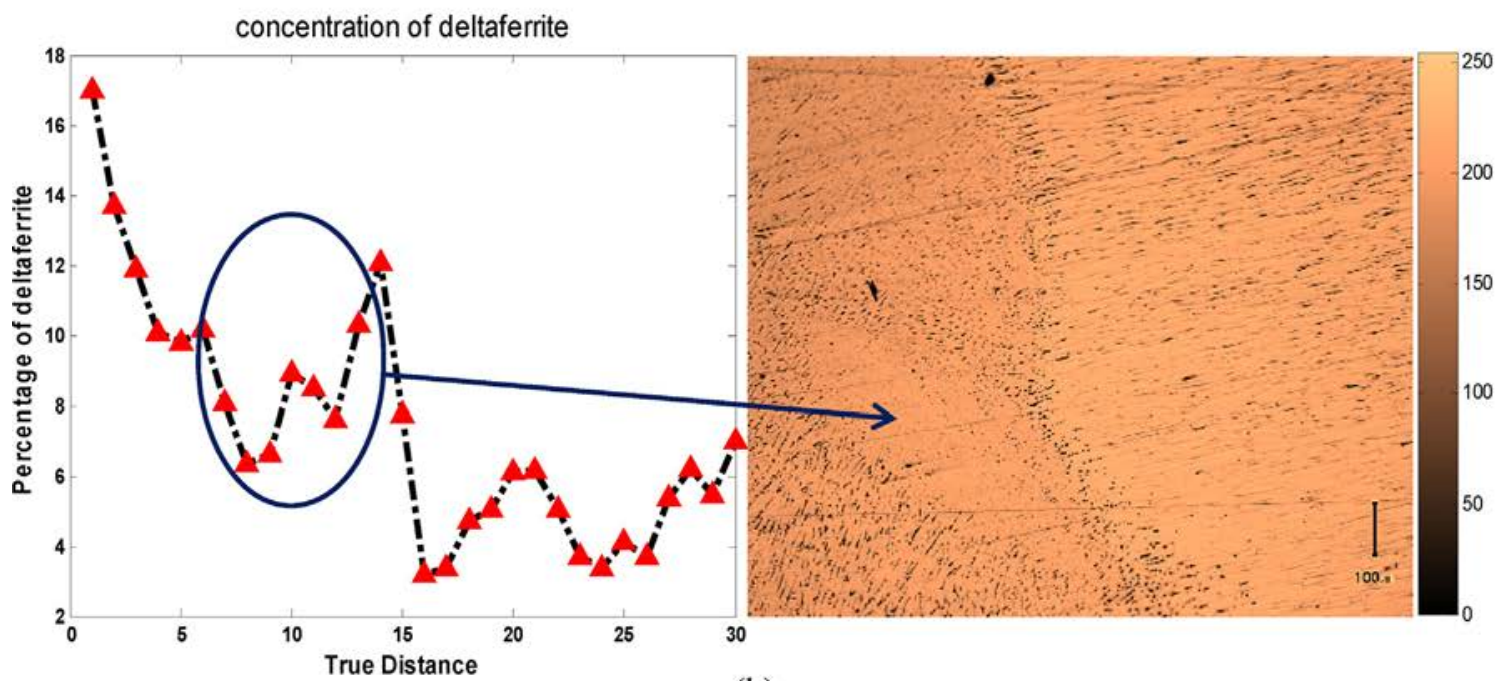

(b)

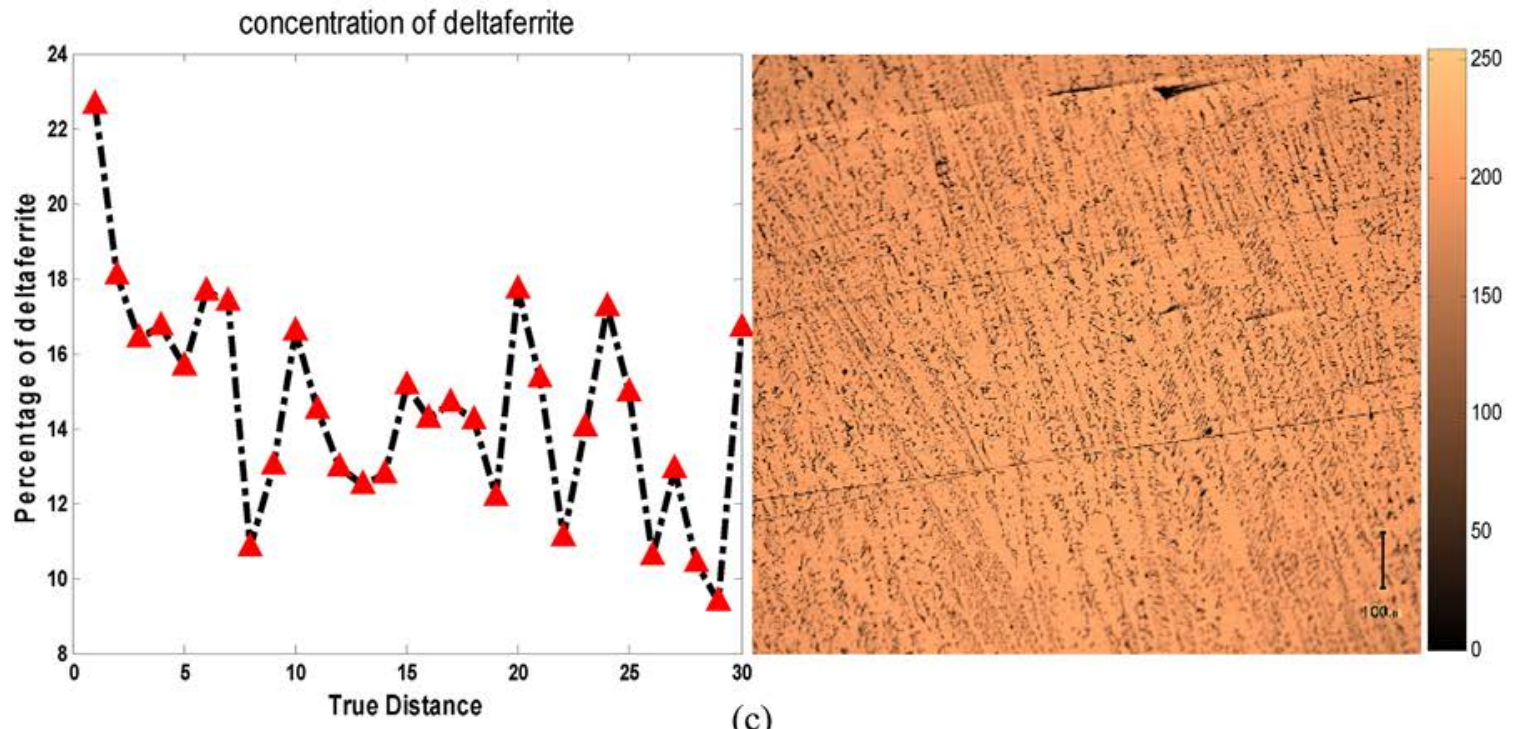

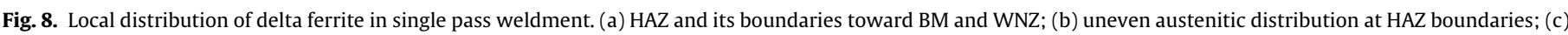
estimation of lacy and vermicular ferrite bands within WNZ. 

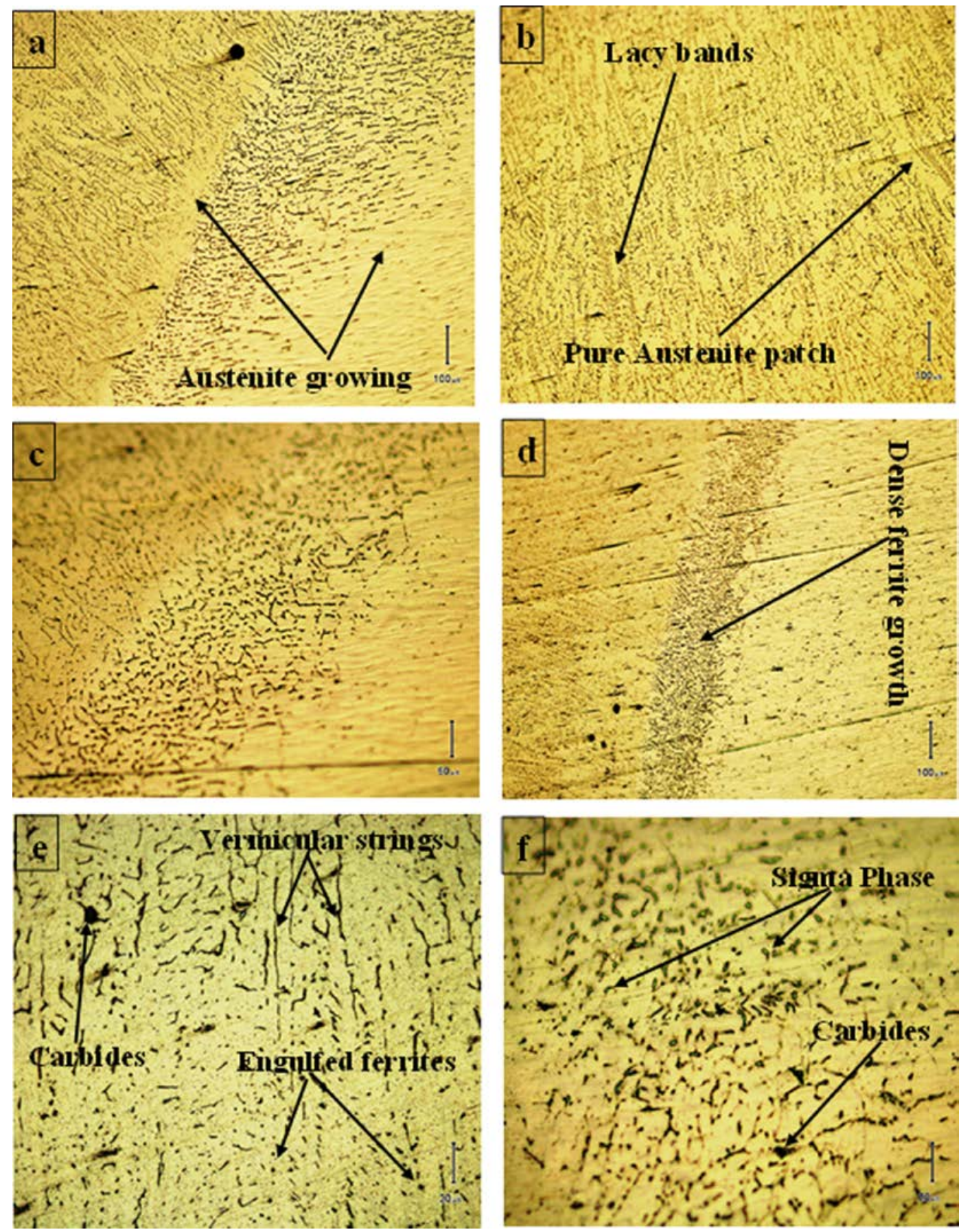

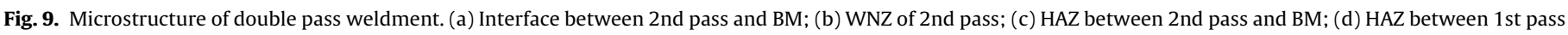
and BM; (e) interface between 2 nd pass and 1st pass; (f) carbides and sigma phase precipitation in HAZ.

The concentration of this phase is higher in HAZ of first pass as compared to that of second pass. However, this higher value of HAZ also incorporates $1-2 \%$ of sigma phase, carbide and silicate precipitates. Reduction of delta ferrite sharp after HAZ toward FZ is higher in first pass as compared to second pass. Successive decrement of ferrite percentage in HAZ of second pass toward base metal shows tendency toward grain growth.

\subsubsection{Triple pass}

In triple pass SMAW, the microstructure of each pass is totally different with respect to delta ferrite morphology, size, concentration and solidification behavior of austenitic phase due to abrupt thermal changes and heat input. The ferritic concentration in third pass is higher as compared to second one due to long thick columnar delta ferrites. During the solidification of triple pass firstly nucleation of delta ferrite is taken place then inter dendritic spaces are filled with the austenitic phase grown epitaxially from base metal. Parallel relation developed between heat source motion and direction of growth of ferrites and austenite.

This parallel behavior becomes the strong reason for long columnar shaped ferrites with planer austenite. Due to high heat input, improper nucleated delta ferrites are shifted to sigma phase as shown in Fig. 11. At the HAZ of third pass and BM, the thermal gradient and heat source direction supports the planer growth of 

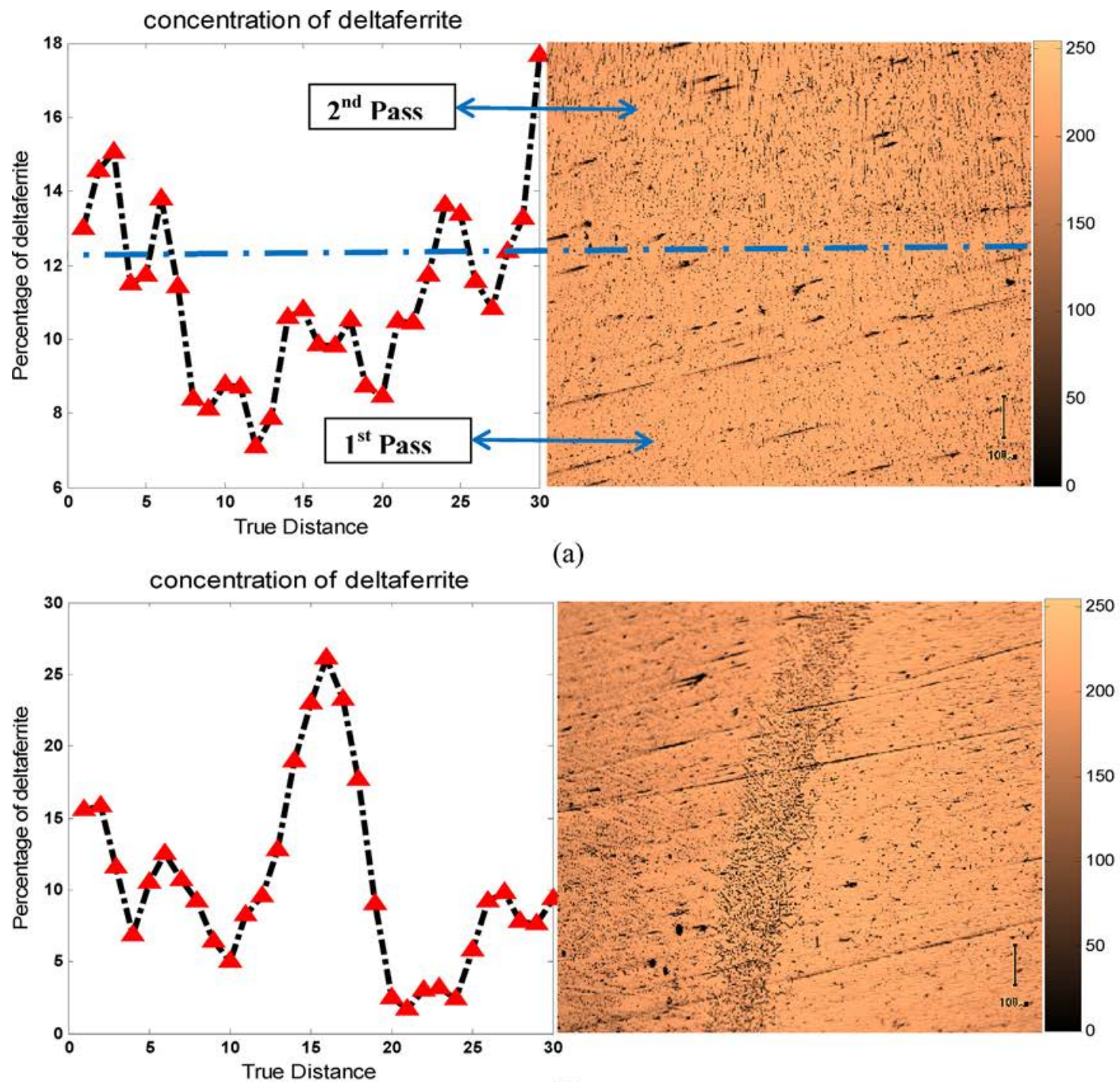

(b)

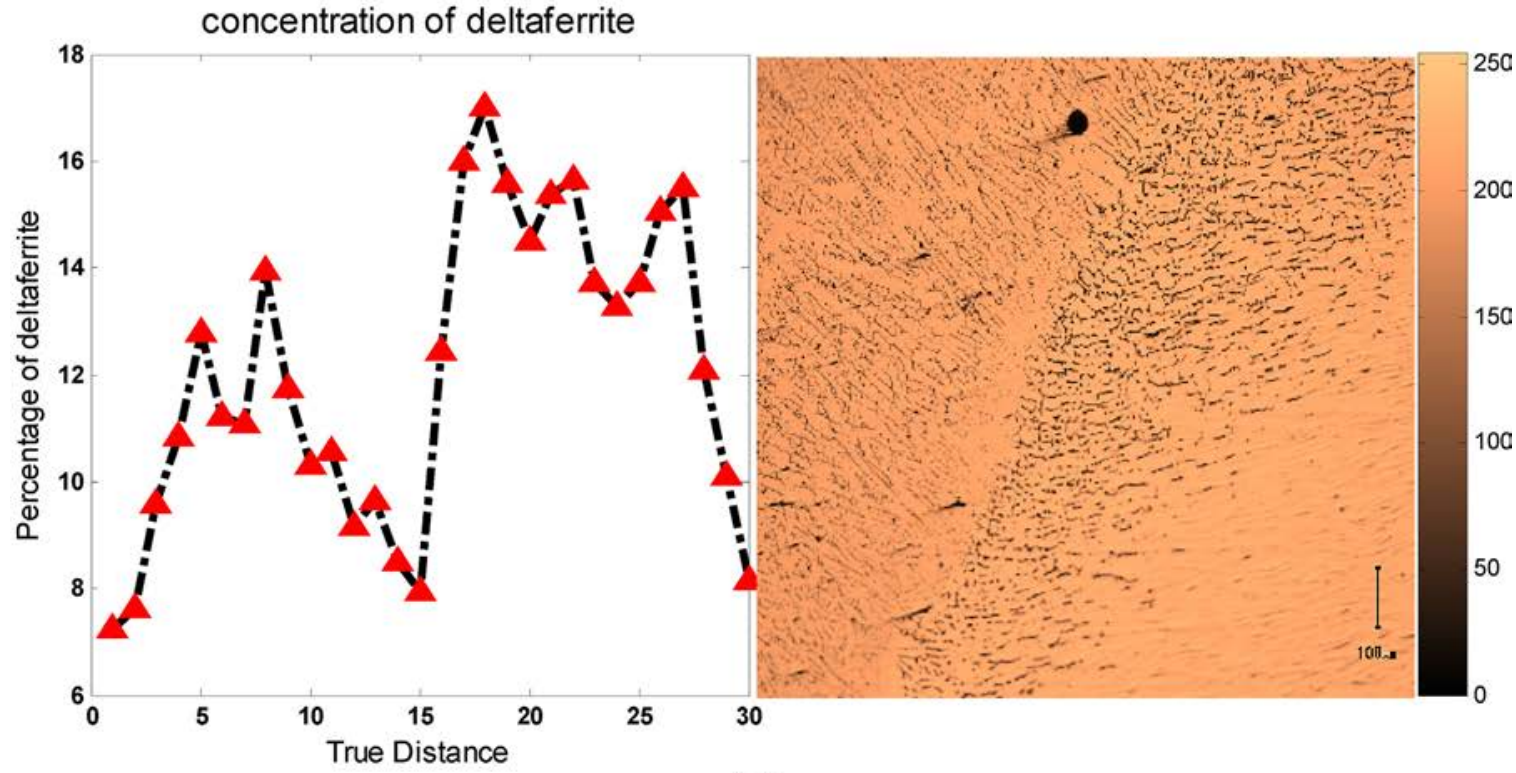

(c)

Fig. 10. Local distribution of delta ferrite in double pass weldment. (a) Interface between 2nd pass and 1st pass; (b) HAZ between 1st pass and BM; (c) HAZ between 2nd pass and BM. 

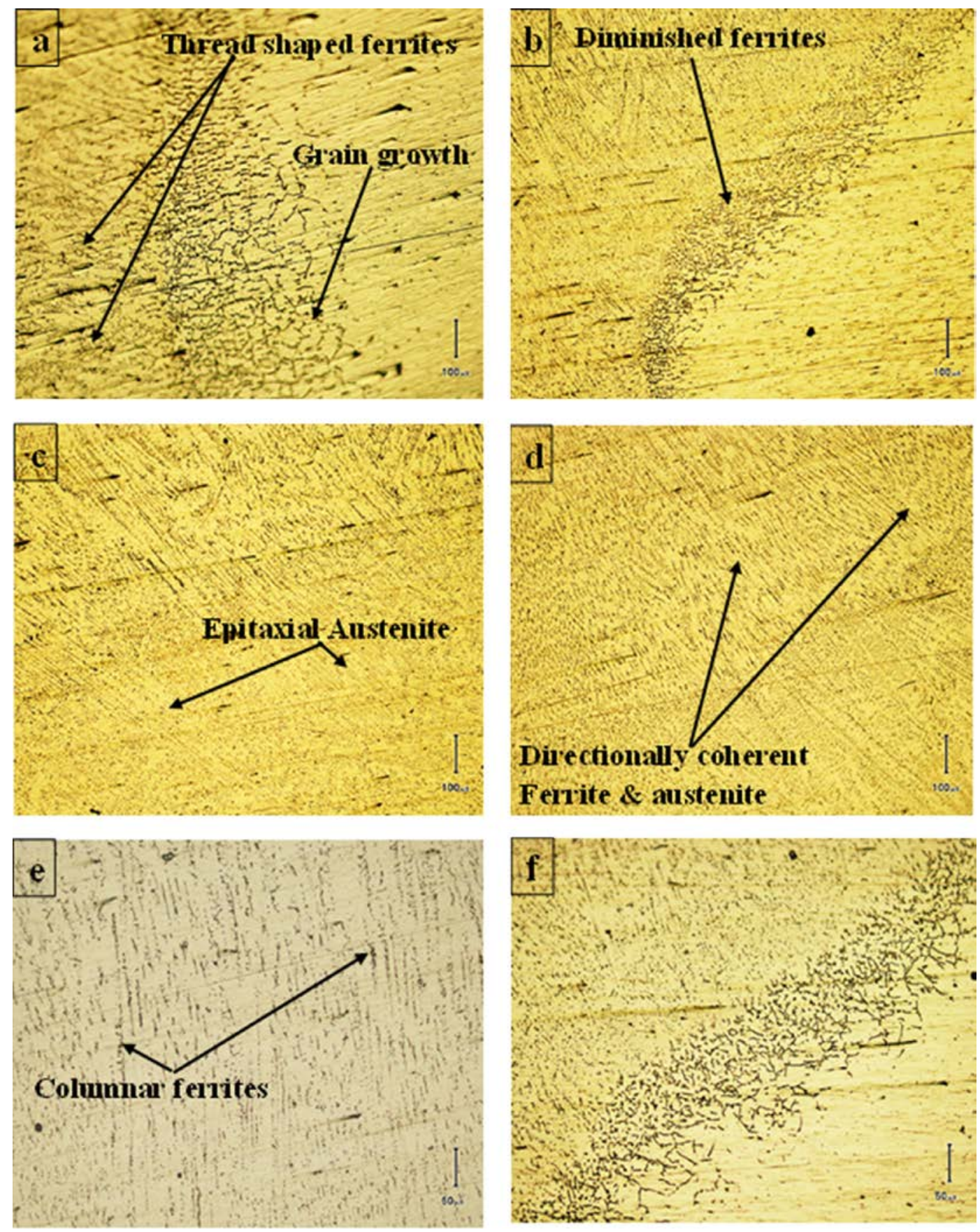

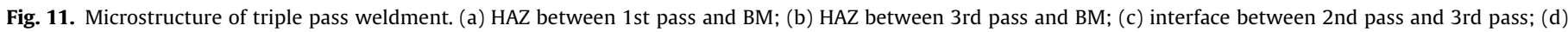
interface between 2 nd pass and 1st pass; (e) WNZ of 3rd pass; (f) HAZ of 3rd pass.

austenite (overlay the base metal) as compared to ferrite nucleation. Previous literature shows that the growth of this epitaxial austenite rejects the $\mathrm{Cr}$ toward liquid. So at fusion boundaries this $\mathrm{Cr}$ becomes responsible for a massive ferrite nucleation. High heat input suppressed the growth of nucleated ferrite present at HAZ periphery near to third pass FZ but this size is gradually increases toward BM. No columnar pattern is observed near the HAZ which is probably due to direction variation between heat source motion and microstructural species growth. Second pass is the only pass of triple pass weldment having lacy ferrite morphology. While in first pass due to effects of later passes maximum phase shifting occurred, resultantly thread type minute delta ferrites are seen as shown in Fig. 11. The HAZ between first pass and BM shows grain growth with thin boundaries. However, the HAZ of second and third pass is nearly same with a little difference of cooling time. Due to this difference the nucleation of delta ferrite which is suppressed in third pass is continuously enhanced in second pass. However, maximum $\mathrm{Cr}$ migration toward HAZ is observed in second pass as compared to third and first pass. It is also exposed from the microstructure of different passes that the width of ferrite free zones between the passes varies continuously. It may happen due to varying of SMAW parameters like as welding speed, arc length and arc force etc. At this stage it is not possible to maintain a regular thickness of delta ferrite patch due to complicated nature of its controlling parameters and moreover it is also not the objective of this research. 

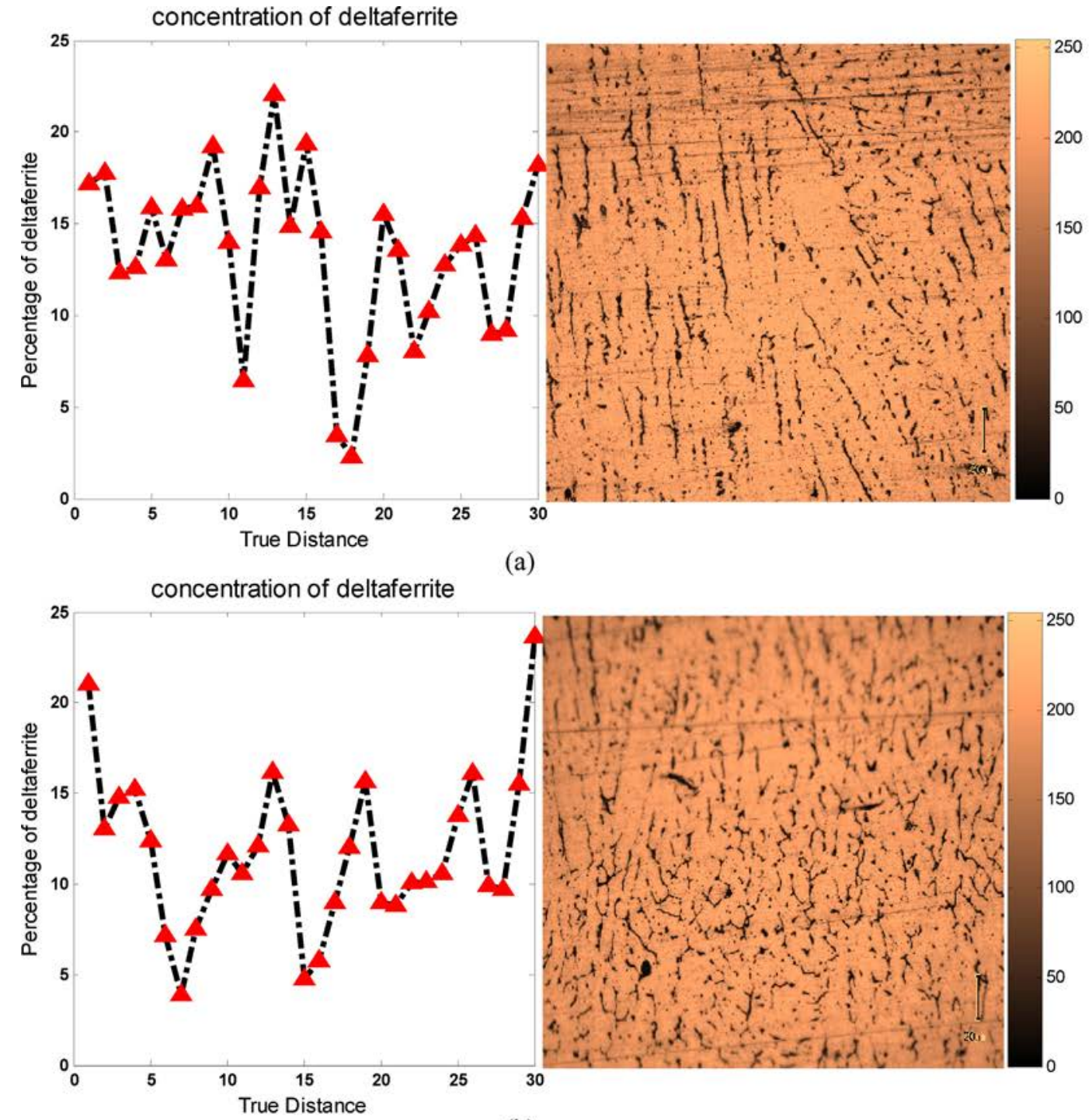

(b)

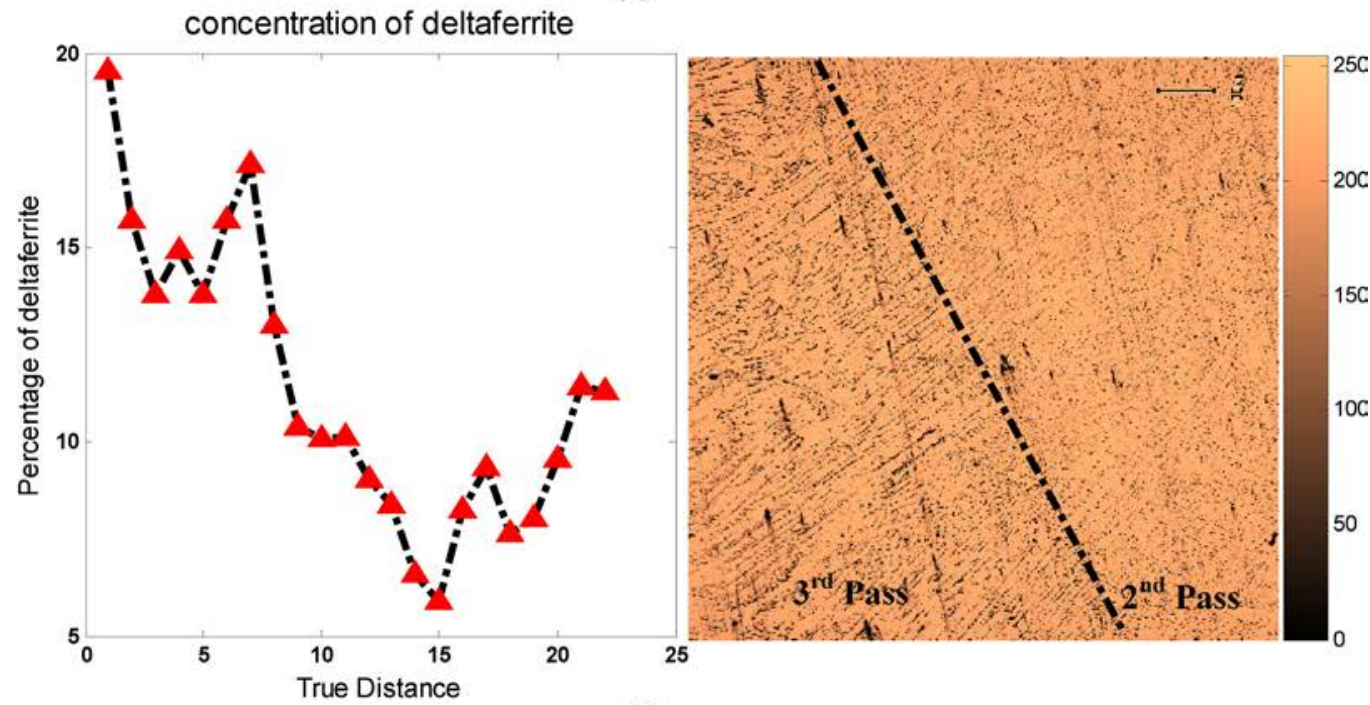

(c)

Fig. 12. Local distribution of delta ferrite in triple pass weldment. (a) WNZ of 3rd pass; (b) WNZ of 2nd pass; (c) interface between 3rd pass and 2nd pass. 


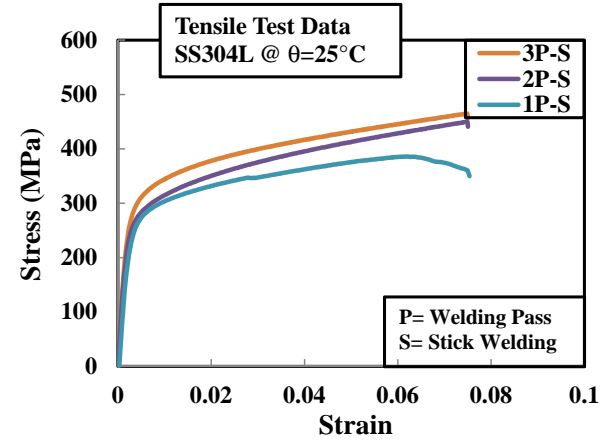

Fig. 13. Tensile strength of different pass weldments (graph lines are in sequence with the legend order)

The local percentage of delta ferrite in different zones of triple pass weldment is shown in Fig. 12. In third pass, the percentage of delta ferrite has the maximum value along the ferritic column and it suddenly decreased right after the column due to presence of planer epitaxial austenite. After some columns the delta ferrite percentage do not decreased as expected and it is due to presence of tiny particle of sigma phase in solidified austenite phase.

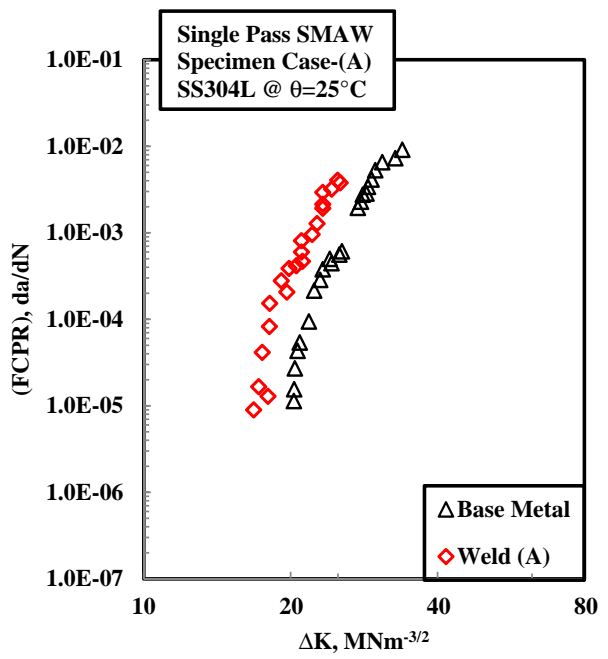

(a)

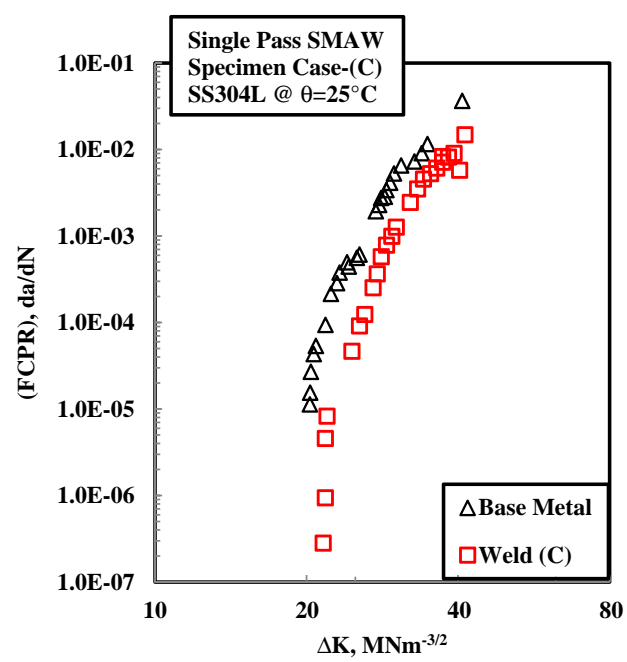

(c)
The almost uniformity in upper and lower extremes of delta ferrite percentage curve of second pass is due to proper orientation of lacy ferrite morphology. The ferrite percentage is always in decreasing manner at the junction of two passes in triple pass weldment.

\subsection{Hardness}

From Table 4, it is generally observed that the hardness of FZ is higher than HAZ and BM for a specific welding pass.

As the chemical composition of BM and filler metal is same for all passes weldment so difference in hardness values might be due to varying thermal profile, concentration of alloying elements and morphology of delta ferrite as well. Hardness value at some points present in heat affected and weld nugget zones is sudden increased. This abrupt change in hardness is due to different types of carbide precipitates. In FZ, lacy ferrites show more hardness as compared to vermicular ferrites. It is also observed that the reduction in delta ferrite size is also the cause of lowering hardness values. Dendritic growth has lower hardness value as compared to planer epitaxial solidified austenitic phase in FZ. In HAZ the grain growth behavior leading to reducing grain size and increasing grain boundaries is responsible for decreasing hardness values. However the increasing

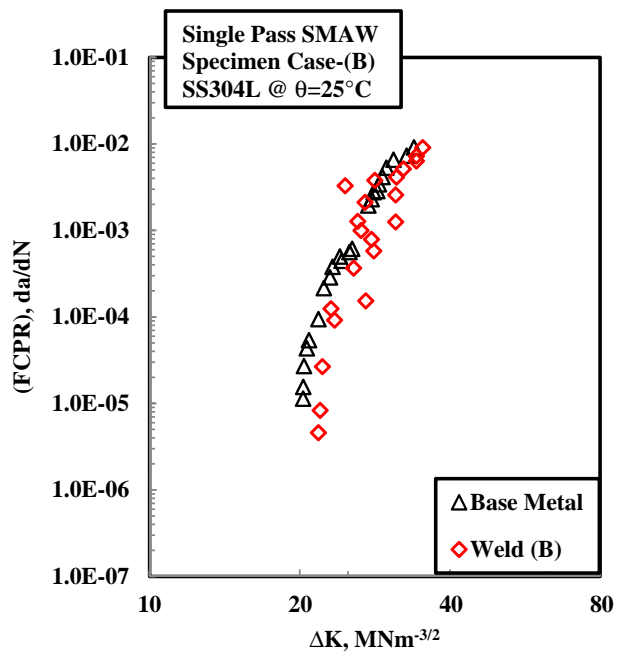

(b)

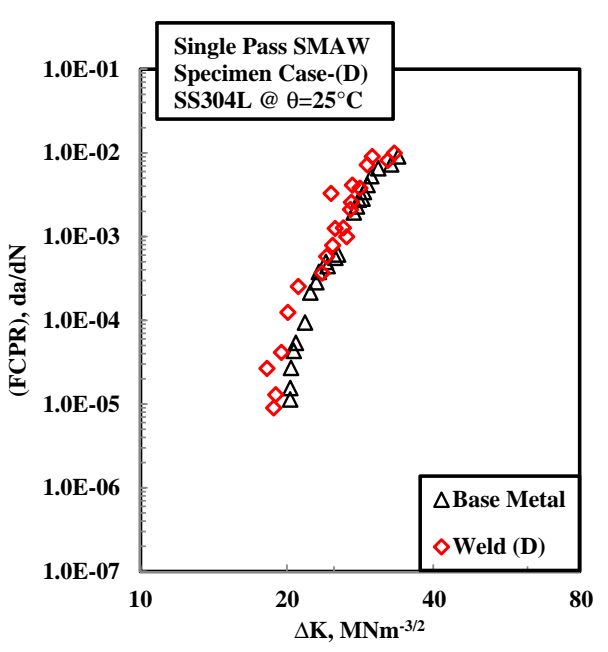

(d)

Fig. 14. FCPR in single pass weldment. 


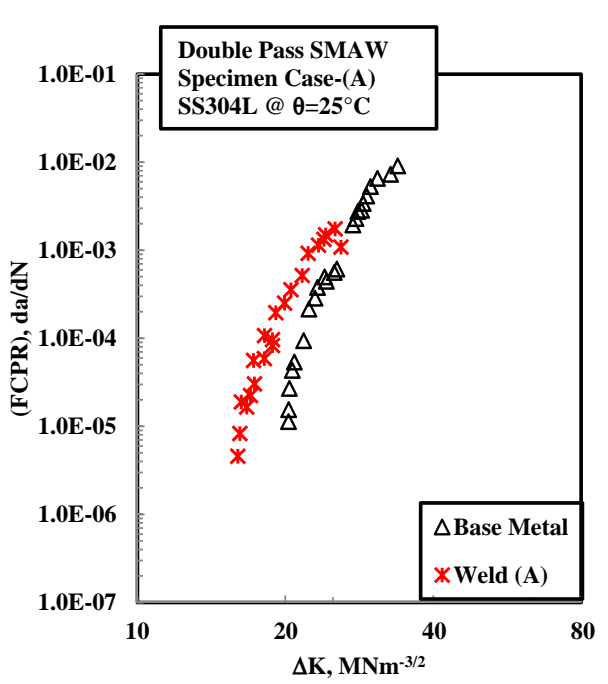

(a)

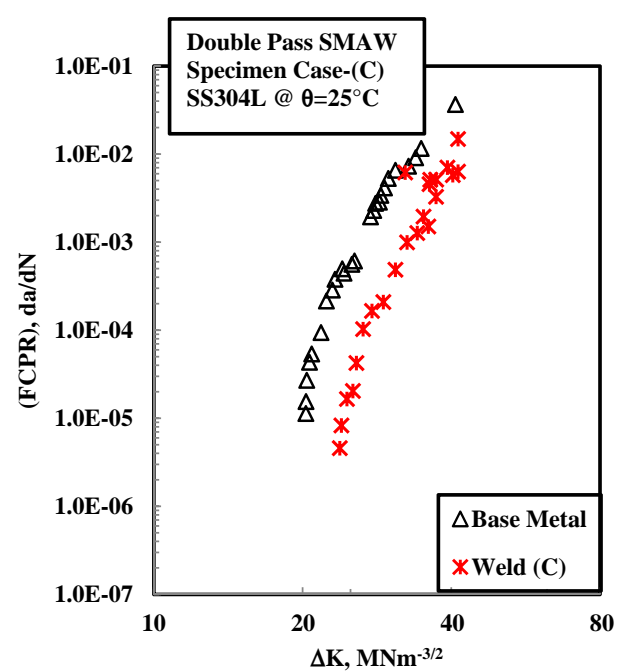

(c)

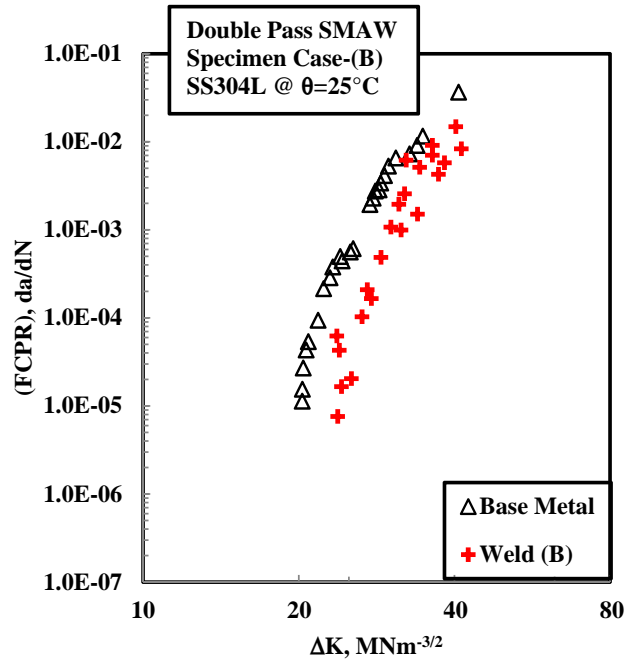

(b)

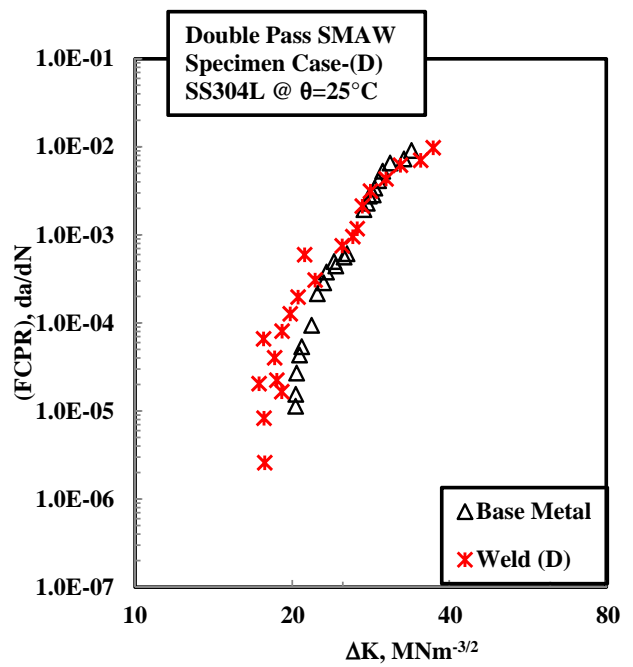

(d)

Fig. 15. FCPR in double pass weldment.

value of hardness in HAZ's of double and triple passes as compared to single one is due to tendency of formation of mature grains as a result of reheating.

\subsection{Tensile tests}

Tensile strength of base metal at room temperature is $565 \mathrm{MPa}$. Due to SMAW its value is notably reduced. The tensile strength of different pass weldments is shown in Fig. 13.

Triple pass weldment has highest value as compare to other passes. The reduction in tensile strength of triple double and single pass is $17.88 \%, 21.07 \%$, and $31.86 \%$ respectively. Slow cooling rate due to high input in single pass weldment is the main cause of tensile strength decline. Ferrite free zones near HAZ also play a supporting role to decrease the tensile strength. In double and triple pass weldments, ductility of the joint is enhanced due to fine distribution of delta ferrite in austenitic patches near HAZ. It may possible that ferrite morphology also has some effects on tensile strength but it really needs an extensive research furthermore.

\subsection{Impact tests}

At room temperature, the impact toughness of unwelded BM (SS304L) is $216 \mathrm{~J}$. The impact value is successively decreased as the number of passes increased. The impact values of single double and triple pass weldments are 172, 164 and $153 \mathrm{~J}$ respectively. From single to triple pass, the reduction in toughness values is

Table 4

Hardness results of different zones of different pass weldments.

\begin{tabular}{|c|c|c|c|c|c|c|}
\hline \multirow[t]{2}{*}{ Zone } & \multirow[t]{2}{*}{ Single pass weldment } & \multicolumn{2}{|c|}{ Double pass weldment } & \multicolumn{3}{|c|}{ Triple pass weldment } \\
\hline & & 1st pass & 2nd pass & 1st pass & 2nd pass & 3rd pass \\
\hline BM & 159 & 159 & 159 & 159 & 159 & 159 \\
\hline $\mathrm{HAZ}$ & 167 & 176 & 179 & 178 & 182 & 186 \\
\hline WNZ & 186 & 190 & 195 & 194 & 196 & 199 \\
\hline
\end{tabular}




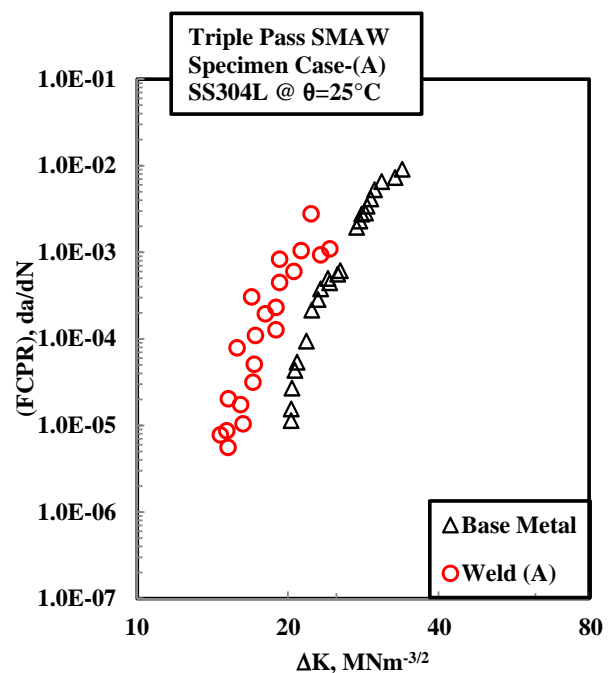

(a)

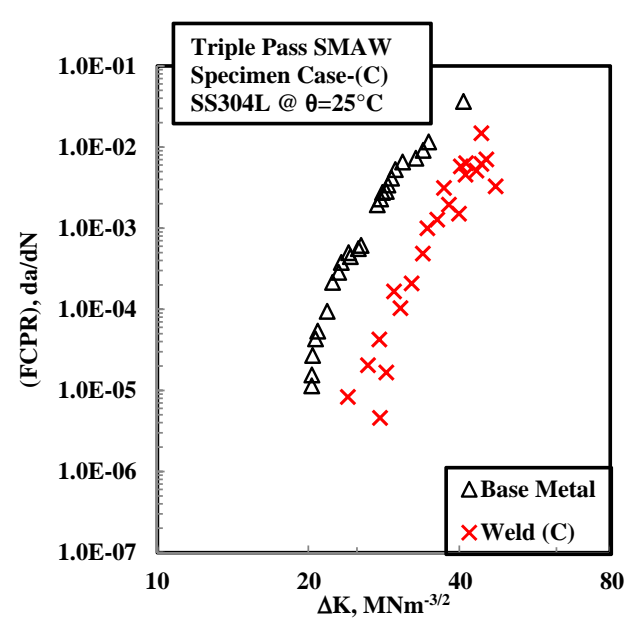

(c)

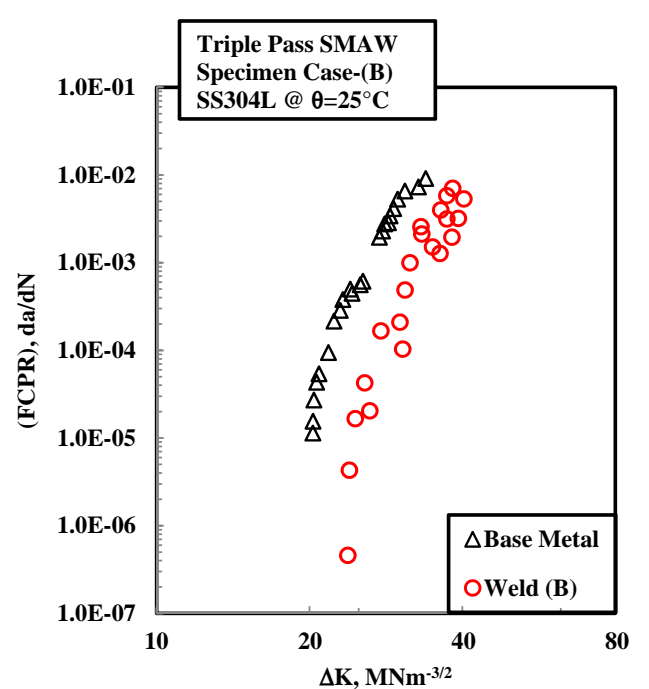

(b)

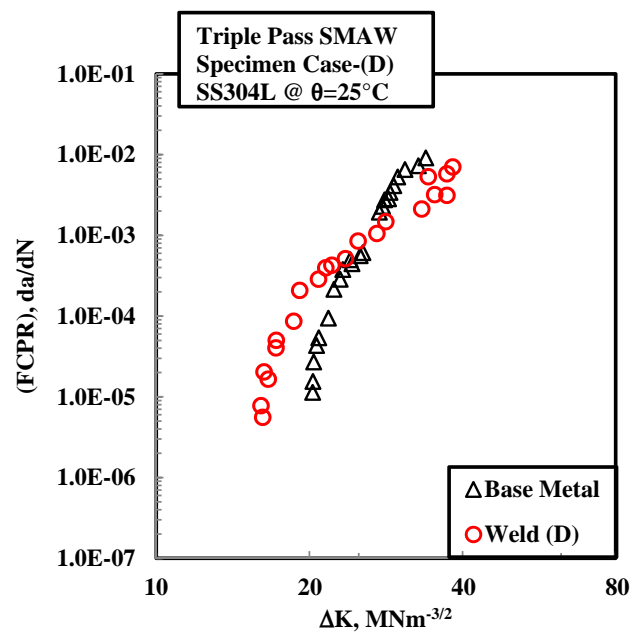

(d)

Fig. 16. FCPR in triple pass weldment.

$20.5 \%, 24 \%$ and $29 \%$ respectively. The variations between impact strength values are due to increasing micro voids and imperfection as a result of increasing passes. As the toughness of welded specimens is directly related to delta ferrite so its quality, crystallographic orientation and morphology are prime factors to control the impact strength. Less impact values in double and triple pass weldments are also due to sigma phase origination at ferrite boundaries.

\subsection{Fatigue tests}

Delta ferrite density and orientation as a result of multi pass SMAW have a gigantic connection with placement of fatigue cracks, their preferentially growing direction and propagation rate. Fatigue crack propagation rate (FCPR) at different zones of weldments is determined by using conventional Paris law [32] (Eq. (4))

$\frac{d a}{d N}=C \Delta K^{m}$

where, $\Delta K=$ stress intensity factor. $C, m=$ Paris constants.

Here, the constants ' $C$ ' and ' $m$ ' represent the propagation of cracks at lower loads and slope of FCP curve respectively. During fatigue cycling, the data acquisition system (DAS) of MTS-810 saves each increment in fatigue crack length against its respective cycle. Each value of crack length $(a)$ and corresponding number of cycles $(N)$ is subtracted from the next greater value of data series. To obtain $\mathrm{d} a / \mathrm{d} N$, results of two subtractions are divided (Eq. (5)).

$\frac{d a}{d N}=\left(a_{\max }-a_{\min }\right) /\left(N_{\max }-N_{\min }\right)$

For the values of stress intensity factor, $K$, Eq. (6) is followed.

$K=\left(\frac{P}{B \sqrt{W}}\right) \cdot f\left(\frac{a}{w}\right)$

where, $f(a / W)$ is known as geometric correction factor for $C(T)$ specimen. It totally depends on fatigue crack length to specimen width ratio.

$$
\begin{aligned}
& f\left(\frac{a}{W}\right.
\end{aligned}
$$

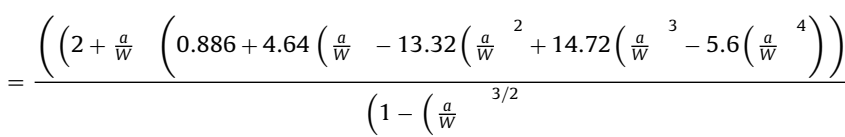


Paris curves are developed between ' $\Delta K$ ' and crack propagation speed ' $\mathrm{d} a / \mathrm{d} N$ ' for four different cases of crack initiation.

\subsubsection{Single pass}

The initiation and propagation behavior of fatigue cracks for single pass SMAW is totally different at different location of weldment. The lowest fatigue life is observed for case-A. The most prone nature to fatigue cracks is due excessive number of ferrite-austenite interfaces. As the austenite and ferrite has face centered cubic (FCC) and body centered cubic (BCC) crystal structures respectively so at the interface of these two species a crystallographic discrepancy is always happened. This mismatch of atomic structure is responsible for generation of micro cracks. With increasing number of cycles, these micro cracks coalesce and resultantly macro crack initiation generation is taken place.

Irrespective of the case- $\mathrm{A}$, in case-D the notch tip is oriented perpendicularly to HAZ of this weldment type. From Fig. 14 it is depicted that the fatigue cracks face more resistance in this orientation as compared to case-A.

The slow propagation rate is due to rare growth of fine sized grain and maximum availability of single phase austenitic matrix at the boundaries of HAZ and BM. However, directional difference of tensile residual stresses and applied load is also the main cause of hindrance in fatigue crack initiation. The FCPR near the boundaries of HAZ and FZ is reduced due to appearance of totally new microstructure of FZ. In case-B the additional residual stresses directional effects along with the stress concentration at the edges of crystallographic inhomogeneity are responsible for its less fatigue life as compared to case-C. From local percentage of ferrite at $\mathrm{FZ}$ it is found that crack propagation rate is slightly increased at the region of vermicular ferrites as compared to lacy ferrite. It may due to stress concentration as a result of surface curvature at the periphery of vermicular ferrites.

\subsubsection{Double pass}

The overall trend of curves of all cases is same as represented previously with a different initiation situation and propagation rate. Due to heat input variation along the thickness of specimen at HAZ, large microstructural deviations are observed. In case-A the micro crack initiation is started at the HAZ of first pass due to clustering of small sized ferrite. These particle nature ferrites increase the area of contact with austenite and density of interfaces. The fatigue crack in first pass always leads the cracks in second pass, where the ferrites are in mature condition relatively. A pretty good amount of sigma phase particles in HAZ of first pass is also a reason of early crack generation and rapid propagation. Directionally effects of sigma phase particles on FCPR are still unknown. In case$\mathrm{D}$ after some crack length the rate is suddenly reduced. It is due to the varying ferrites shape near FZ in first pass.

From the comparison of case-B and ' $C$ ' it is concluded that fatigue crack propagation is slow in lacy ferrite in parallel direction as compared to perpendicular one. In these cases as shown in Fig. 15, the initiation of crack is same but propagation is faster in case-B after a specific crack length.

\subsubsection{Triple pass}

Due to repetitive heating and cooling as a result of second and third passes and interpasses cooling, the phase shifting from austenite to ferrite also plays a considerable effect on fatigue crack initiation and propagation rate. Actually the density of dislocations is higher in austenitic matrix as compared to newly formed ferrites. So due to this reason, these ferrites become the hindrance places in the way of gliding dislocations. Resultantly, dislocations pile up at ferrites and generate local stress concentration leading to fatigue crack initiation. These local stresses are most effective in case-A as compared to case-D. In case-A the most fragile zone for crack is HAZ of the first pass. An interesting thing in case-D is that although the fatigue crack initiation stage is same as in case-A, but this zone is highly resistive for crack propagation as shown in Fig. 16. It reflects that the microstructural zone which is best suited for crack initiation must not always be same for propagation stage. It means fatigue properties of welded stainless steel are not only controlled by microstructure, but also mechanics based because the mechanics of fatigue crack initiation is totally different to its propagation. In case-B the micro cracks are formed by coalescence because inter dendritic distance is very short. So fatigue crack just followed the path of these micro cracks due to which propagation rate is higher as compared to case-C. Carbides of alloying elements also play their role to enhance the FCPR. At the boundaries of two zones in cases$\mathrm{C}$ and $\mathrm{D}$, It is observed that FCPR is increased as compared to its previous propagation rate within a distinct zone.

\section{Conclusions}

A comprehensive research with a series of experiments on multipass SMAW and its effects on mechanical properties, microstructure and FCPR in different zones of SS304L weldments are made. From this research the following points are concluded;

1. In multipass pass SMAW, each pass has its distinct effect on the microstructure of BM, HAZ and FZ due to variations in heat input experienced by the specimen. Microstructure of each pass weldment contains primary austenite with different morphologies and size of delta ferrites. Some precipitates of carbides and sigma phase particles are also found at high heat input zone as well as on immature grain growth sites.

2. Hardness is increased with increasing number of passes due to thermal grain refinement as a result of additional heat input in later passes. Heating history placed also its importance in this regard as the hardness of second passes is not same in double and triple pass weldments.

3. Tensile strength of triple pass weldment is greater as compared to other passes due to excessive, well defined bands of lacy ferrites, oriented longitudinally. Almost 4-5\% reduction in impact strength is observed as the number of welding passes increased. The decrement in fracture toughness is due to rapid phase shifting at the boundaries of ferrites along with clustering of small sized grain boundaries.

4. Consistent local percentage detection of delta ferrite used in this research provides more useful information as compared to few FN values. However, the technique used in this research is not much more useful in the case of appearance of excessive carbides and sigma phase particles.

5. Lacy ferrites to total ferrites ratio only depends on heat input. It is not affected by the chemical composition. Most of the carbide precipitation is observed near vermicular ferrites. The preferential growth of lacy ferrite is detected on the top most pass of welding in case of multiple passes.

6. Highest percentage of delta ferrite is observed at HAZ as compared to BM and FZ regardless of number of passes. It is due to accumulation of ferrite stabilizer alloying elements. Epitaxial growth of austenite near the boundaries of HAZ is attributed to diffusion effects. Direction of heat source motion also plays its role for defining ferrite morphology as well as crystallographic harmony of austenite with ferrite.

7. Fatigue life of triple pass weldment is found highest. HAZ is the most fragile zone for fatigue crack propagation. For all cases (A, B, C and D), it is noticed that FCPR is retarded when crack propagates in normal direction to weldment. It is due to directional effects of tensile residual stresses. Vermicular ferrite is ideal morphology for fatigue crack initiation. Lacy ferrites are 
more resistant to crack propagation in perpendicular direction to crack tip. In single pass weldment, crack propagates faster due to small particle nature of ferrites. Short vermicular ferrites with inverted edges are ideal sites for crack imitation but not much for crack propagation showing mechanics controlled crack driving factors are dominating over microstructural effects.

\section{Acknowledgements}

The authors are happy to acknowledge Chinese Government support. They are cordially thankful to Prof. Dr. Ghulam Yasin Chohan, Director UCET, University of Sargodha, for his support and encouragement. Authors thank Engr. Faisal Qayyum, Engr. Fariha Mukhtar \& Mr. Aman Ullah for their experimental and computational assistance as well as technical guidance for specimen preparations.

\section{References}

[1] Peckner D, Bernstein IM. Handbook of stainless steels. New York, NY: McGrawHill; 1977.

[2] Society AW. Welding handbook. American Welding Society; 1950.

[3] Mohandas T, Reddy GM, Naveed M. A comparative evaluation of gas tungsten and shielded metal arc welds of a "ferritic" stainless steel. J Mater Process Technol 1999;94:133-40

[4] Muller A. Electric arc welding. Google Patents; 1950

[5] Lee W-S, Cheng J-I, Lin C-F. Deformation and failure response of 304L stainless steel SMAW joint under dynamic shear loading. Mater Sci Eng A 2004;381:206-15

[6] Folkhard E. Welding metallurgy of stainless steels. Springer Science \& Business Media; 2012.

[7] Mateša B, Samardžić I, Dunđer M. The influence of the heat treatment on delta ferrite transformation in austenitic stainless steel welds. Metalurgija 2012;51:229-32.

[8] Dippenaar RJ, Phelan DJ. Delta-ferrite recovery structures in low-carbon steels. Metall Mater Trans B 2003;34:495-501.

[9] James M, Webster P, Hughes D, Chen Z, Ratel N, Ting S-P, et al. Correlating weld process conditions, residual strain and stress, microstructure and mechanical properties for high strength steel-the role of neutron diffraction strain scanning. Mater Sci Eng A 2006;427:16-26.

[10] McGuire MF. Stainless steels for design engineers. ASM International; 2008

[11] Shankar V, Gill T, Mannan S, Sundaresan S. Criteria for hot cracking evaluation in austenitic stainless steel welds using longitudinal varestraint and transvarestraint tests. Sci Technol Weld Join 2000;5:91-7.
[12] Suresh S. Fatigue of materials. Cambridge, UK: Cambridge University Press: 1991. p. 211

[13] Hertzberg RW. Deformation and fracture mechanics of engineering materials; 1989.

[14] Hull F. Delta ferrite and martensite formation in stainless steels. Weld J $1973 ; 52: 193$

[15] Kou S. Welding metallurgy. Cambridge Univ Press; 1987.

[16] Ren S, Ma Z, Chen L. Effect of welding parameters on tensile properties and fracture behavior of friction stir welded Al-Mg-Si alloy. Script Mater 2007;56:69-72.

[17] Brooks J, Thompson A. Microstructural development and solidification cracking susceptibility of austenitic stainless steel welds. Int Mater Rev 1991;36:16-44.

[18] Maddox S. Review of fatigue assessment procedures for welded aluminium structures. Int J Fatigue 2003;25:1359-78.

[19] Zhang Y-H, Maddox SJ. Fatigue life prediction for toe ground welded joints. Int J Fatigue 2009;31:1124-36.

[20] Oh J, Kim NJ, Lee S, Lee EW. Correlation of fatigue properties and microstructure in investment cast Ti-6Al-4V welds. Mater Sci Eng A 2003:340:232-42.

[21] Hasçalik A, Ünal E, Özdemir N. Fatigue behaviour of AISI 304 steel to AISI 4340 steel welded by friction welding. J Mater Sci 2006;41:3233-9.

[22] Ullah M, Pasha RA, Chohan GY, Qayyum F. Numerical simulation and experimental verification of CMOD in CT specimens of TIG welded AA2219-T87. Arab J Sci Eng 2015;40:935-44.

[23] Shah M, Ali M, Sultan A, Mujahid M, Mehmood H, Dar NU, et al. An investigation into the fatigue crack growth rate of electron beam-welded $\mathrm{H} 13$ tool steel: effect of welding and post-weld heat treatment. Metallogr Microstruct Anal 2014;3:114-25.

[24] Tsay L, Huang W, Chen C. Assisted crack growth in maraging steel welds by gaseous hydrogen. Fatigue Fract Eng Mater Struct 1997;20:1033-41.

[25] Jiang W, Wang B, Gong J, Tu S. Finite element analysis of the effect of welding heat input and layer number on residual stress in repair welds for a stainless steel clad plate. Mater Des 2011;32:2851-7.

[26] Rho BS, Hong HU, Nam SW. The fatigue crack initiation at the interface between matrix and $\delta$-ferrite in 304L stainless steel. Scr Mater 1998;39:1407-12.

[27] Rho BS, Hong HU, Nam SW. The effect of $\delta$-ferrite on fatigue cracks in 304L steels. Int J Fatigue 2000;22:683-90.

[28] Lin Y, Lin Y, Chen S, Liu Z. Role of retained ferrite on the thermal fatigue cracking resistance in martensitic stainless steel weldment. Mater Sci Eng A 2003:339:133-5

[29] Siewert T, McCowan C, Olson D. Ferrite number prediction to $100 \mathrm{FN}$ in stainless steel weld metal. Weld J 1988;67:289-98.

[30] Vitek J, David S, Hinman C. Improved ferrite number prediction model that accounts for cooling rate effects. Part 1: Model development. Weld J (New York) 2003; $82: 10-S$.

[31] Farrar J. The measurement of ferrite number (FN) in real weldments-final report. Weld World 2005:49:13-21.

[32] Paris P, Erdogan F. A critical analysis of crack propagation laws. J Fluids Eng $1963 ; 85: 528-33$ 